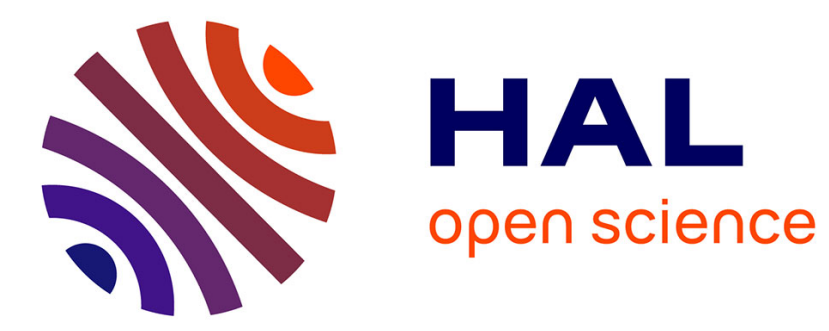

\title{
Food powders: Surface and form characterization revisited
}

Ingrid Murrieta-Pazos, C. Gaiani, Laurence Galet, Rachel Calvet, Bernard Cuq, J. Scher

\section{- To cite this version:}

Ingrid Murrieta-Pazos, C. Gaiani, Laurence Galet, Rachel Calvet, Bernard Cuq, et al.. Food powders: Surface and form characterization revisited: Review. Journal of Food Engineering, 2012, 112 (1-2), pp.1 - 21. 10.1016/j.jfoodeng.2012.03.002 . hal-01268290

\section{HAL Id: hal-01268290 \\ https://hal.science/hal-01268290}

Submitted on 26 Apr 2019

HAL is a multi-disciplinary open access archive for the deposit and dissemination of scientific research documents, whether they are published or not. The documents may come from teaching and research institutions in France or abroad, or from public or private research centers.
L'archive ouverte pluridisciplinaire HAL, est destinée au dépôt et à la diffusion de documents scientifiques de niveau recherche, publiés ou non, émanant des établissements d'enseignement et de recherche français ou étrangers, des laboratoires publics ou privés. 


\title{
Food powders: Surface and form characterization revisited
}

\author{
I. Murrieta-Pazos ${ }^{\text {a,b }}$, C. Gaiani ${ }^{\text {a,* }}$, L. Galet ${ }^{\text {b }}$, R. Calvet ${ }^{\text {b }}$, B. Cuq ${ }^{\text {c }}$, J. Scher ${ }^{\text {a }}$ \\ ${ }^{a}$ Université de Lorraine, LIBio, 2 Avenue de la forêt de Haye, B.P. 172, 54505 Vandœuvre-lès-Nancy, France \\ ${ }^{\mathrm{b}}$ Université de Toulouse, Mines Albi, Centre RAPSODEE, CNRS, UMR 5302, Campus Jarlard, 81013 Albi Cedex 09, France \\ ${ }^{\mathrm{C}}$ Montpellier SupAgro INRA, UMR 1208 Unit for Emerging Technology and Polymer Engineering, 2, Place Viala, 34060 Montpellier Cedex 1, France
}

\section{A B S T R A C T}

The amount of interesting methods that allow surface characterisation of food powders, both those recently used and in development, are growing. Until now, a major problem facing researchers and manufacturers was the lack of a central source of information to provide practical knowledge focused only on food powder surfaces and form. The first goal of this review is to present recent and innovating methodologies used to characterize the surface and form of various food powders. In addition, relationships between food powders surfaces (surface energy, composition, structure, etc.) as well as form and functional properties (wettability, caking, flowability, etc.) are highlighted.

Keywords:

Food powders

Surface characterization

XPS

AFM

ICG

Functional properties

\section{Contents}

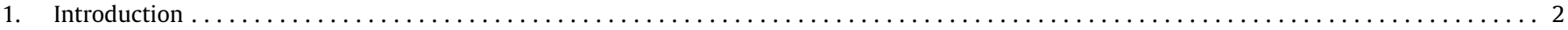

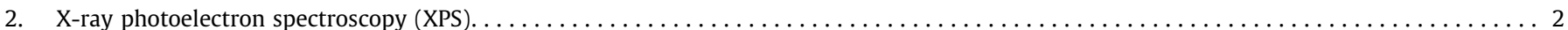

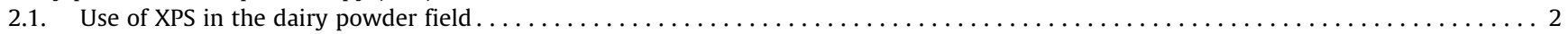

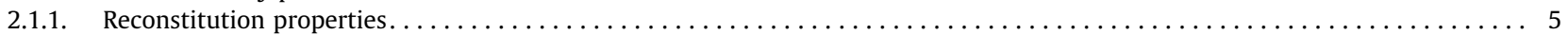

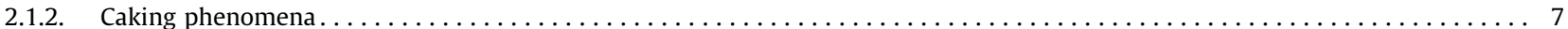

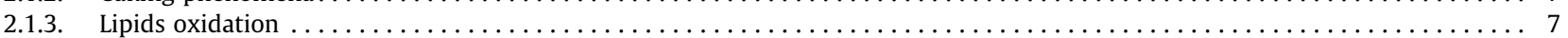

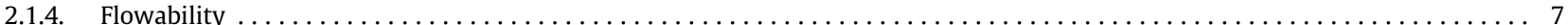

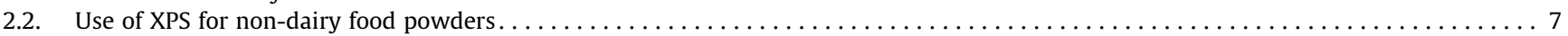

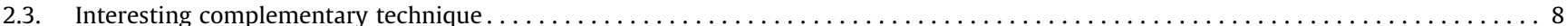

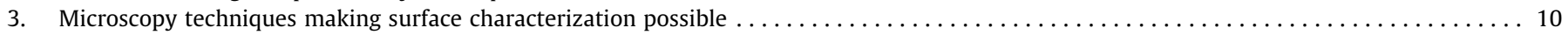

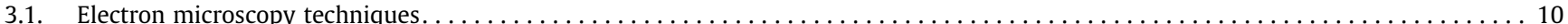

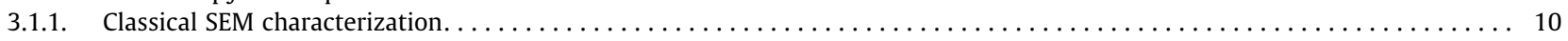

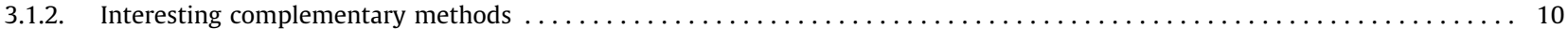

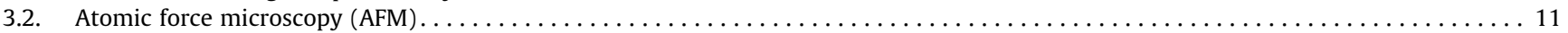

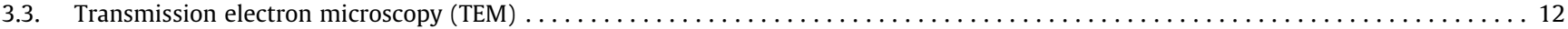

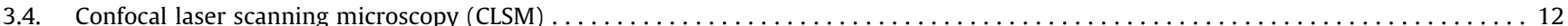

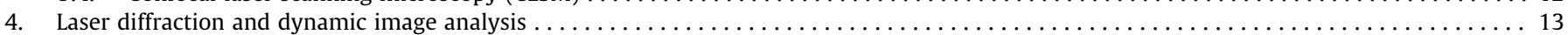

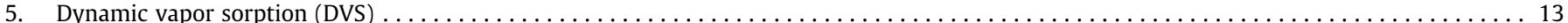

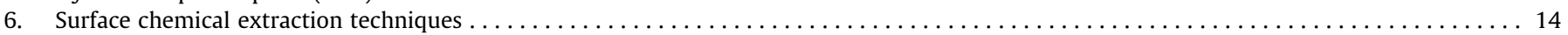

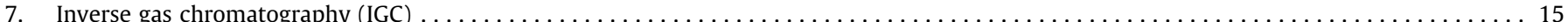

7.1. IGC and moisture adsorption isotherms to investigate interactions between humidity and food components ............ 15

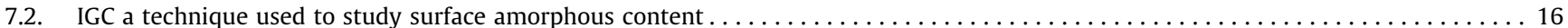

\footnotetext{
* Corresponding author. Tel.: +33 (0) 383595877; fax: +33 (0) 383595804

E-mail address: claire.gaiani@ensaia.inpl-nancy.fr (C. Gaiani).
} 


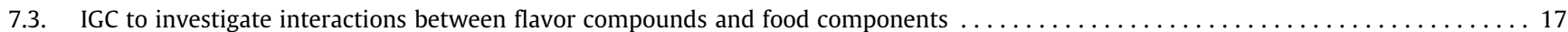

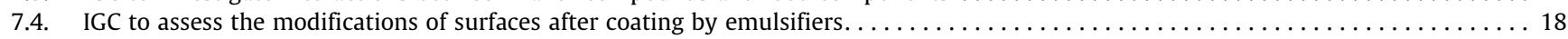

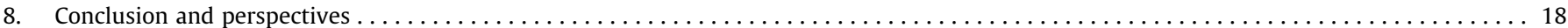

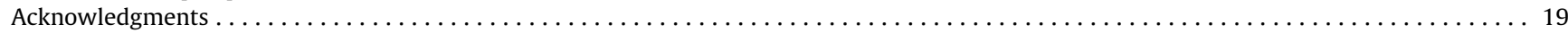

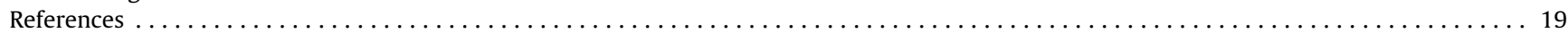

\section{Introduction}

These last 10 years, a lot of food products have been developed and commercialized in a powdered form. As a consequence, a new branch of science and engineering may be identified. Such discipline deals with the integration of fundamental scientific fields (process engineering, particle engineering, surface physics and chemistry, physico-chemistry) within some applied scientific fields (food biochemistry, food technology, functional properties, and food quality) (Cuq et al., 2011; Ortega-Rivas, 2009).

For the food industry, the interest with powder forms is mainly linked to their stability (chemical and microbiological), to the reduced transport costs and general convenience. In industry powders can be considered as end products (sugar, salt, coffee, spices, dried milk...) and also as intermediate products between several industries; for example, those producing powders and alternatively those using powders as ingredients for food products (fruits, starch, eggs, milk, cereals, etc.). For consumers, quick and complete reconstitution of these products is one of the main quality indicators (Forny et al., 2011). Food powders represent a large variety of powder materials that differ in their chemical composition and physical characteristics. Sources of food powders are as diverse as food in general (Fig. 1), therefore differences in forms, structures, composition and behaviors of food powders can be better understood by knowing powders' origins (Cuq et al., 2011). It is important to remark that powders can also be a mix of ingredients making its composition and study more complex.

However, scientific and technical descriptions of the food powder properties remain incomplete. It is known that the characteristics and the properties of the particles (and more particularly the surface properties) play a central role in the mechanisms involved during powders production (milling, spray drying, or crystallization), and use (storage, flow, agglomeration, dispersion, solubilisation...). Until now, the properties of food powders are classically described using bulk parameters. Nevertheless, it is being recognized that the functional properties of food powders are largely dependent of the surface composition and surface characteristics of the particles (Gaiani et al., 2006; Kim et al., 2002; Millqvist-Fureby et al., 2001). This is one of the reasons why several powder properties may be explained by a better knowledge and characterization of particle surfaces and physical and/or chemical interactions among them and their environment (Gaiani, 2006; Kim, 2008). The characteristics of the particle surface may depend on different factors: bulk composition, operating conditions and storage conditions (Fig. 2).

Powder surface investigation requires very precise and elaborate techniques. Until now few investigations have been applied to food powder surfaces. Consequently research is still limited and this is the reason why the development of new surface characterization techniques may be an extensive field to exploit with considerable interest to the food industry.

This review is going to highlight the experimental techniques that enable the characterization of food powders surfaces and, when it is reported, to connect this information with their functional properties.

\section{X-ray photoelectron spectroscopy (XPS)}

XPS $^{1}$ (also called ESCA or electron spectroscopy for chemical analysis) is an analytical technique widely used in surface analysis (Briggs, 1994; Rouxhet and Genet, 2011). It provides elemental and chemical state data from the first nanometers of the surface of solid samples. The sample is placed in an ultra high vacuum and irradiated with photons from a soft X-ray source with a well defined energy. The method is based on surface irradiation which causes a complete transfer of photon energy to atomic electrons (Bosquillon et al., 2004). When the electron binding energy $\left(E_{b}\right)$ is lower than the photon energy $(h v)$, the electron is emitted from the atom with a kinetic energy $\left(E_{k}\right)$ equal to the difference between the photon energy and the binding energy, minus the spectrometer work function $\Phi$ :

$E_{k}=h v-E_{b}-\Phi$

Because XPS is an ultra high vacuum technique $\left(10^{-8} \mathrm{kPa}\right)$, it may presents limitations for food with water present, but not for powdered food (James and Smith, 2009).

\subsection{Use of XPS in the dairy powder field}

The first developments using this equipment in the field of dairy powders were done by Fäldt (1995). Then, the use of XPS was regularly reported for the determination of the surface composition of dairy powders (Kim et al., 2002, 2009a-c; Gaiani et al., 2006, 2007; Gaiani et al., 2010, 2011a; Millqvist-Fureby et al., 2001; MillqvistFureby and Smith, 2007; Shrestha et al., 2007) and sugar mixed with dairy proteins powders (Jayasundera et al., 2010, 2011a-c) at an elemental level. From the $\mathrm{C}, \mathrm{O}$ and $\mathrm{N}$ percentages, surface contents in protein, lactose and lipids were calculated with a matrix formula where the elemental composition in the sample is assumed to be a linear combination of pure components making up the sample (Kim et al., 2002; Gaiani et al., 2006; Jayasundera et al., 2009). Milk powders are generally composed of lipids, proteins and lactose but also vitamins and traces of mineral elements. By using the precedent matrix, only lactose, lipids and proteins were taken into account; other components were neglected (Fäldt, 1995; Gaiani et al., 2006; Kim, 2008).

One of the most important results obtained with this technique concerned the over-representation of some components at the powder surface in comparison with the bulk composition (Shrestha et al., 2007; Kim et al., 2002; Gaiani et al., 2006; Vignolles et al., 2009). Lipids and proteins (surface active components) were systematically found over-represented at the surface whereas lactose was less represented (Tables 1a, 1b and 1c). Indeed, when fat is present in the formulation, even in very low quantity, for

${ }^{1}$ Abbreviations: AFM, atomic force microscopy; CLSM, confocal laser scanning microscopy; PL, phospholipids; CP, cream powder; DSC, differential scanning calorimetry; DVS, dynamic vapor sorption; EDX, energy dispersive X-ray spectroscopy; ESCA, electron spectroscopy for chemical analysis; GAB, Guggenheim-Anderson-Boer; HPLC, high performance liquid chromatography; GC, gas chromatography; IGC, inverse gas chromatography; MPC, milk proteins concentrate; NMC, native micellar casein; NL, neutral lipids; NWI, native whey isolate; RH, relative humidity; SEM, scanning electron microscopy; SMP, skim milk powder; SMPG, skim milk powder granulated; SPI, soy protein isolate; TEM, transmission electron microscopy; ToF-SIMS, time of flight secondary ion mass spectrometry; WMP, whole milk powder; WMPG, whole milk powder granulated; XPS, X-ray photoelectron spectroscopy. 


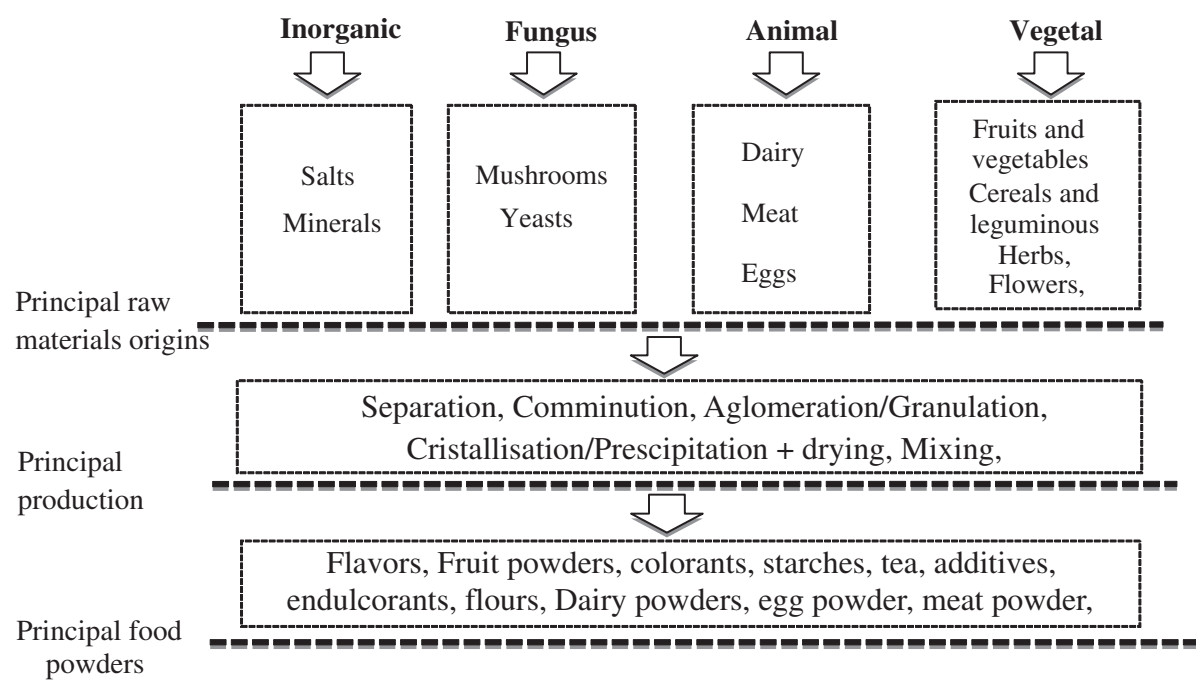

Fig. 1. Principal origins of food powders.

example the skim milk powder, the fat is still present at the surface. Alternatively, protein will govern the surface in absence of lipids or share the surface with the fat present. Nevertheless, the lipids cover the majority of the surface in the presence of both components. Finally, lactose was observed in the interior of the particle after free fat extraction (Table 1c).
This tendency to observe an overrepresentation of the lipids and then the proteins at the surface, is observed at all production scales, independent of the production conditions. Results for laboratory (Table 1a), pilot (Table $1 \mathrm{~b}$ ) and industrial (Table 1c) dryers are shown confirming this tendency.

Raw material
nature

Physicochemical properties, Preparation process, Bulk composition,

Quality, Source origins, Physic characteristics

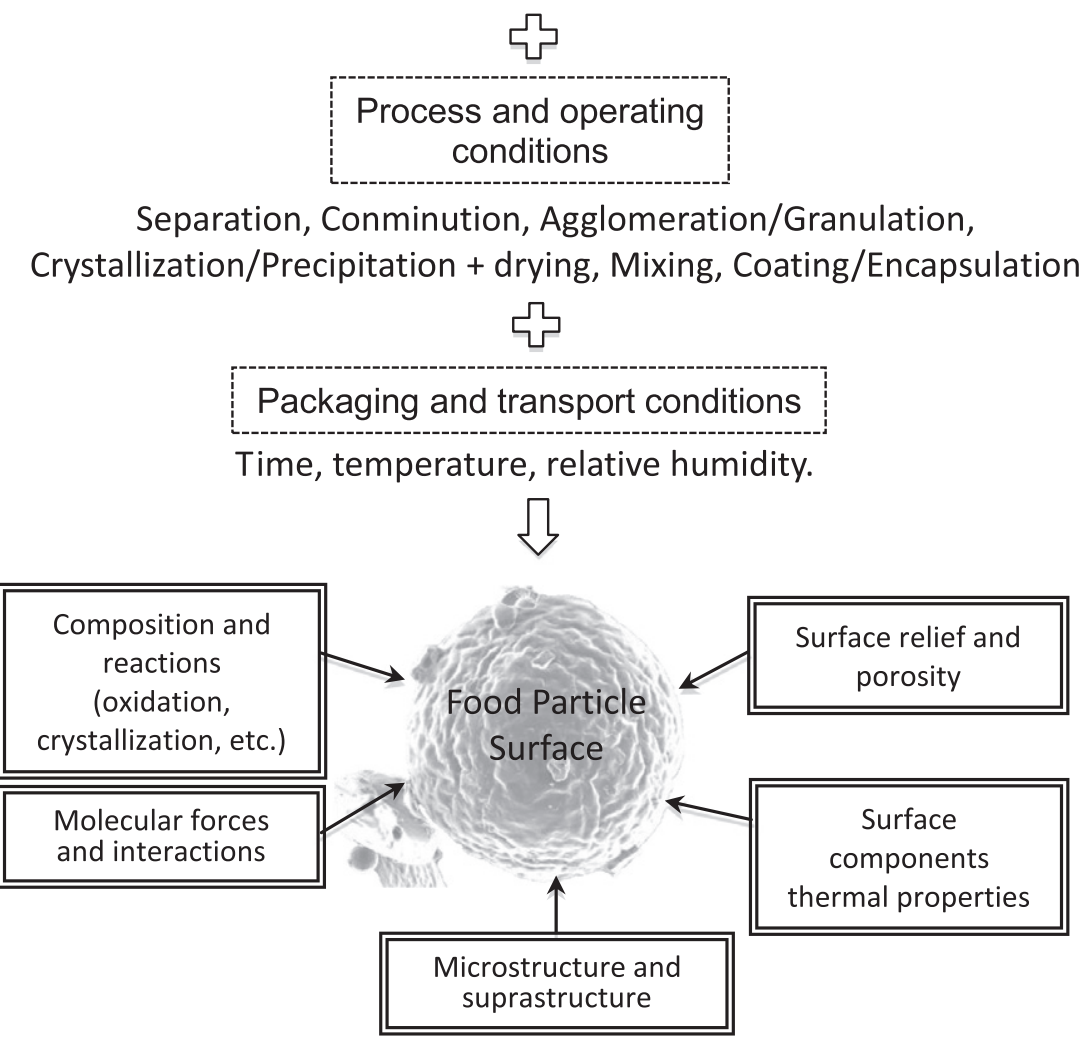

Fig. 2. Factors affecting the powder surfaces properties. 
Table 1a

Bulk composition and surface composition obtained from XPS and linear equation relating elemental components to lactose, protein and fat in milk powders and milk subproduct powders obtained from lab scale spray dryers.

\begin{tabular}{|c|c|c|c|c|c|c|c|}
\hline Powder system & $\begin{array}{l}\text { Feed solids } \\
(\%)\end{array}$ & $\begin{array}{l}\text { Number of homogenization } \\
\text { passes }\end{array}$ & $T_{\text {in }} / T_{\text {out }}\left({ }^{\circ} \mathrm{C}\right)$ & $\begin{array}{l}\% \text { Of surface } \\
\text { lactose (bulk) }\end{array}$ & $\%$ Of surface proteins (bulk) & $\begin{array}{l}\% \text { Of surface } \\
\text { fat (bulk) }\end{array}$ & References \\
\hline WMP-SMP $1.1 \%$ fat & 41.2 & - & $120 / 80$ & $41^{*}(59.6)$ & $51^{*}(39.3)$ & $8^{*}(1.1)$ & Nijdam and Langrish (2006) \\
\hline WMP-SMP $1.8 \%$ fat & 41.2 & - & $120 / 80$ & $35^{*}(59.2)$ & $45^{*}(39.0)$ & $20^{*}(1.8)$ & \\
\hline WMP-SMP $3.4 \%$ fat & 41.2 & - & $120 / 80$ & $31^{*}(58.3)$ & $38^{*}(38.4)$ & $31^{*}(3.4)$ & \\
\hline WMP-SMP $6.7 \%$ fat & 41.2 & - & $120 / 80$ & $29^{*}(56.3)$ & $33^{*}(37.0)$ & $38^{*}(6.7)$ & \\
\hline WMP-SMP $14.0 \%$ fat & 41.2 & - & $120 / 80$ & $23^{*}(52.1)$ & $24^{*}(33.9)$ & $53^{*}(14.0)$ & \\
\hline WMP-SMP $29.8 \%$ fat & 41.2 & - & $120 / 80$ & $19^{*}(43.0)$ & $21^{*}(27.3)$ & $60^{*}(29.8)$ & \\
\hline WMP-SMP $1.1 \%$ fat & 41.2 & - & $200 / 125$ & $52^{*}(59.6)$ & $31^{*}(39.3)$ & $17^{*}(1.1)$ & \\
\hline WMP-SMP $1.8 \%$ fat & 41.2 & - & $200 / 125$ & $42^{*}(59.2)$ & $29^{*}(39.0)$ & $29^{*}(1.8)$ & \\
\hline WMP-SMP $3.4 \%$ fat & 41.2 & - & $200 / 125$ & $36^{*}(58.3)$ & $28^{*}(38.4)$ & $36^{*}(3.4)$ & \\
\hline WMP-SMP $6.7 \%$ fat & 41.2 & - & $200 / 125$ & $35^{*}(56.3)$ & $24^{*}(37.0)$ & $41^{*}(6.7)$ & \\
\hline WMP-SMP $14.0 \%$ fat & 41.2 & - & $200 / 125$ & $27^{*}(52.1)$ & $24^{*}(33.9)$ & $49^{*}(14.0)$ & \\
\hline WMP-SMP $29.8 \%$ fat & 41.2 & - & $200 / 125$ & $20^{*}(43.0)$ & $16^{*}(27.3)$ & $64^{*}(29.8)$ & \\
\hline SMP:Lac (3:1) & 35 & - & $180 / 80$ & $29(63)$ & $61(26)$ & $10(1)$ & Shrestha et al. (2007 \\
\hline SMP:Lac $(1: 1)$ & 35 & - & $180 / 80$ & $31(75)$ & $58(17)$ & $11(0.8)$ & \\
\hline SMP:Lac (1:3) & 35 & - & $180 / 80$ & $39(88)$ & $57(9)$ & $5(0.25)$ & \\
\hline SMP & 10 & - & $145 / 85$ & $10^{*}(51.0)$ & $46^{*}(36.0)$ & $44^{*}(1.0)$ & Kim et al. (2009c) \\
\hline SMP & 20 & - & $145 / 85$ & $16^{*}(51.0)$ & $48^{*}(36.0)$ & $35^{*}(1.0)$ & \\
\hline SMP & 30 & - & $145 / 85$ & $51^{*}(51.0)$ & $24^{*}(36.0)$ & $25^{*}(1.0)$ & \\
\hline SMP & 10 & - & $205 / 105$ & $18^{*}(51.0)$ & $48^{*}(36.0)$ & $34^{*}(1.0)$ & \\
\hline SMP & 20 & - & $205 / 105$ & $22^{*}(51.0)$ & $50^{*}(36.0)$ & $28^{*}(1.0)$ & \\
\hline SMP & 30 & - & $205 / 105$ & $29^{*}(51.0)$ & $51^{*}(36.0)$ & $20^{*}(1.0)$ & \\
\hline WMP & 10 & 6 & $145 / 85$ & $0^{*}(36.6)$ & $3^{*}(27.9)$ & $97^{*}(26.6)$ & \\
\hline WMP & 20 & 6 & $145 / 85$ & $0^{*}(36.6)$ & $3^{*}(27.9)$ & $97^{*}(26.6)$ & \\
\hline WMP & 30 & 6 & $145 / 85$ & $0^{*}(36.6)$ & $3^{*}(27.9)$ & $97^{*}(26.6)$ & \\
\hline WMP & 10 & 6 & $205 / 105$ & $0^{*}(36.6)$ & $3^{*}(27.9)$ & $97^{*}(26.6)$ & \\
\hline WMP & 20 & 6 & $205 / 105$ & $0^{*}(36.6)$ & $3^{*}(27.9)$ & $97^{*}(26.6)$ & \\
\hline WMP & 30 & 6 & $205 / 105$ & $0^{*}(36.6)$ & $3^{*}(27.9)$ & $97^{*}(26.6)$ & \\
\hline WMP & 10 & 2 & $145 / 85$ & $0^{*}(36.6)$ & $2^{*}(27.9)$ & $98^{*}(26.6)$ & \\
\hline WMP & 20 & 2 & $145 / 85$ & $0^{*}(36.6)$ & $2^{*}(27.9)$ & $98^{*}(26.6)$ & \\
\hline WMP & 30 & 2 & $145 / 85$ & $0^{*}(36.6)$ & $2^{*}(27.9)$ & $98^{*}(26.6)$ & \\
\hline WMP & 10 & 2 & $205 / 105$ & $0^{*}(36.6)$ & $2^{*}(27.9)$ & $98^{*}(26.6)$ & \\
\hline WMP & 20 & 2 & $205 / 105$ & $0^{*}(36.6)$ & $2^{*}(27.9)$ & $98^{*}(26.6)$ & \\
\hline WMP & 30 & 2 & $205 / 105$ & $0^{*}(36.6)$ & $2^{*}(27.9)$ & $98^{*}(26.6)$ & \\
\hline NMC & 15 & - & $-/ 70$ & $0.8(0.2)$ & $93.9(87.3)$ & $5.3(0.3)$ & Gaiani et al. (2010) \\
\hline NWI & 15 & - & $-/ 70$ & $0.1(0.5)$ & $66.1(91.9)$ & $33.8(0.4)$ & \\
\hline $\mathrm{NMC}+\mathrm{Lac}$ & 15 & - & -170 & $14.3(26.6)$ & $76.8(63.1)$ & 8.9 (Tra) & \\
\hline NWI + Lac & 15 & - & -170 & $9.5(28.5)$ & $62.9(64.4)$ & $27.6(0.5)$ & \\
\hline $\mathrm{NMC}+\mathrm{NWI}$ & 15 & - & $-/ 70$ & $0.3(0.3)$ & $89.6(88.8)$ & 10.1 (Tra) & \\
\hline NMC & 15 & - & -180 & $0.6(0.1)$ & $99.4(86.4)$ & $0.0(0.8)$ & \\
\hline NWI & 15 & - & $-/ 80$ & $0.0(0.6)$ & $69.8(92.2)$ & $30.2(0.3)$ & \\
\hline $\mathrm{NMC}+\mathrm{La}$ & 15 & - & $-/ 80$ & $16.0(26.6)$ & $79.3(62.0)$ & $4.7(0.7)$ & \\
\hline NWI + Lac & 15 & - & $-/ 80$ & $12.7(28.9)$ & $66.3(65.7)$ & $21.0(\mathrm{~T})$ & \\
\hline $\mathrm{NMC}+\mathrm{NWI}$ & 15 & - & $-/ 80$ & $0.0(0.6)$ & $95.6(86.1)$ & $4.4(\mathrm{~T})$ & \\
\hline NMC & 15 & - & $-/ 110$ & $2.2(0.1)$ & $97.8(86.7)$ & $0.0(0.5)$ & \\
\hline NWI & 15 & - & $-/ 110$ & $0.0(0.8)$ & $88.6(92.2)$ & $11.4(\mathrm{~T})$ & \\
\hline $\mathrm{NMC}+\mathrm{Lac}$ & 15 & - & $-/ 110$ & $16.5(26.7)$ & $83.5(62.7)$ & $0.0(\mathrm{~T})$ & \\
\hline $\mathrm{NWI}+\mathrm{Lac}$ & 15 & - & $-/ 110$ & $18.8(28.5)$ & $81.1(66.1)$ & $0.1(\mathrm{~T})$ & \\
\hline $\mathrm{NMC}+\mathrm{NWI}$ & 15 & - & $-/ 110$ & $0.2(0.6)$ & $94.3(89.1)$ & $5.5(\mathrm{~T})$ & \\
\hline NMC & 15 & - & $-/ 130$ & $1.5(0.4)$ & $98.5(87.6)$ & $0.0(0.5)$ & \\
\hline NWI & 15 & - & $-/ 130$ & $0.0(1.3)$ & $88.1(92.3)$ & $11.9(0.6)$ & \\
\hline $\mathrm{NMC}+\mathrm{Lac}$ & 15 & - & $-/ 130$ & $19.7(27.9)$ & $80.3(63.2)$ & $0.0(\mathrm{~T})$ & \\
\hline $\mathrm{NWI}+\mathrm{Lac}$ & 15 & - & $-/ 130$ & $20.8(29.3)$ & $79.2(65.6)$ & $0.0(0.5)$ & \\
\hline $\mathrm{NMC}+\mathrm{NWI}$ & 15 & - & $-/ 130$ & $0.0(0.5)$ & $92.9(86.8)$ & $7.1(\mathrm{~T})$ & \\
\hline NMC & 15 & - & $-/ 150$ & $3.5(0.3)$ & 96.5 (86.5) & $0.0(0.3)$ & \\
\hline NWI & 15 & - & $-/ 150$ & $4.0(0.7)$ & $85.4(91.6)$ & $10.6(0.4)$ & \\
\hline $\mathrm{NMC}+\mathrm{Lac}$ & 15 & - & $-/ 150$ & $19.7(25.6)$ & $80.3(63.3)$ & $0.0(\mathrm{~T})$ & \\
\hline NWI + Lac & 15 & - & $-/ 150$ & $19.2(26.6)$ & $77.0(67.8)$ & $3.8(\mathrm{~T})$ & \\
\hline $\mathrm{NMC}+\mathrm{NWI}$ & 15 & - & $-/ 150$ & $0.8(0.5)$ & $99.2(88.7)$ & $0.0(0.6)$ & \\
\hline
\end{tabular}

Lac, lactose; NMC, native micellar casein; NWI, native whey isolate; SMP, skim milk powder; $T_{\text {in }} / T_{\text {out }}$, inlet temperature/outlet temperature; T, Traces; WMP, whole milk powder.

Values directly extracted from graphics.

In laboratory conditions (Table 1a), Nijdam and Langrish (2006) studied 2 drying temperatures and 6 formulations, mixing whole milk powder (WMP) and skim milk powder (SMP) in order to change the lipid concentration. A small change in the average fat content results in a large change in the surface fat coverage, however, the surface fat coverage is less affected by increases in the average fat content at higher fat concentrations. Higher temperature resulted in larger fat and lactose cover. Nevertheless, the aug- mentation of lactose at the surface does not correspond to the protein-lactose proportion in bulk composition. Authors postulate that at lower drying temperatures, protein has more time to migrate to the surface of the droplet before sufficient moisture is evaporated to form a skin. Similar results in terms of lactose-protein surface composition where observed by Shrestha et al. (2007) who studied powders conformed by mixtures of SMP and lactose. Later Kim et al. (2009c) studied 3 solid concentrations in 
Table 1b

Bulk composition and surface composition obtained from XPS and linear equation relating elemental components to lactose, protein and fat in milk powders and milk subproduct powders from pilot scale spray dryers.

\begin{tabular}{|c|c|c|c|c|c|c|}
\hline Powder system & $\begin{array}{l}\text { Evaporation } \\
\text { capacity }\left(\mathrm{kg} \mathrm{h}^{-1}\right)\end{array}$ & $T_{\text {in }} / T_{\text {out }}\left({ }^{\circ} \mathrm{C}\right)$ & $\begin{array}{l}\% \text { Of surface } \\
\text { lactose (bulk) }\end{array}$ & $\begin{array}{l}\% \text { Of surface } \\
\text { proteins (bulk) }\end{array}$ & $\begin{array}{l}\% \text { Of surface } \\
\text { fat (bulk) }\end{array}$ & References \\
\hline NMC & $70-120$ & - & $0.0(0.4)$ & $100.0(86.7)$ & $0.0(0.3)$ & \multirow[t]{3}{*}{ Gaiani et al. (2006 } \\
\hline NMC + Lactose & $70-120$ & - & $8.9(22.1)$ & $89.4(66.3)$ & $1.7(0.4)$ & \\
\hline NMC + Ultrafiltrate & $70-120$ & - & $3.4(21.3)$ & $91.3(62.2)$ & $5.3(0.4)$ & \\
\hline NMC & - & $215 / 70$ & $0(1.5)$ & $94(80.6)$ & $6(0.4)$ & \multirow[t]{13}{*}{ Gaiani et al. (2007) } \\
\hline NMC-A15DS- $20^{\circ} \mathrm{C}-\mathrm{WB}$ & - & $215 / 70$ & $0(1.5)$ & $94(80.6)$ & $6(0.4)$ & \\
\hline NMC-A30DS- $20^{\circ} \mathrm{C}-W B$ & - & $215 / 70$ & $0(1.5)$ & $94(80.6)$ & $6(0.4)$ & \\
\hline NMC-A60DS- $20^{\circ} \mathrm{C}-W B$ & - & $215 / 70$ & $0(1.5)$ & $89(80.6)$ & $11(0.4)$ & \\
\hline NMC-A15DS-20 ㄷ-SB & - & $215 / 70$ & $0(1.5)$ & $94(80.6)$ & $6(0.4)$ & \\
\hline $\mathrm{NMC}-\mathrm{A} 30 \mathrm{DS} 20^{\circ} \mathrm{C}-\mathrm{SB}$ & - & $215 / 70$ & $0(1.5)$ & $87(80.6)$ & $13(0.4)$ & \\
\hline $\mathrm{NMC}-\mathrm{A} 60 \mathrm{DS} 20^{\circ} \mathrm{C}-\mathrm{SB}$ & - & $215 / 70$ & $0(1.5)$ & $83(80.6)$ & $17(0.4)$ & \\
\hline NMC-A15DS- $50{ }^{\circ} \mathrm{C}-W B$ & - & $215 / 70$ & $0(1.5)$ & $94(80.6)$ & $6(0.4)$ & \\
\hline NMC-A30DS- $50{ }^{\circ} \mathrm{C}-W B$ & - & $215 / 70$ & $0(1.5)$ & $94(80.6)$ & $6(0.4)$ & \\
\hline NMC-A60DS-50 ${ }^{\circ} \mathrm{C}-W B$ & - & $215 / 70$ & $0(1.5)$ & $86(80.6)$ & $14(0.4)$ & \\
\hline NMC-A15DS-50 ${ }^{\circ} \mathrm{C}-\mathrm{SB}$ & - & $215 / 70$ & $0(1.5)$ & $94(80.6)$ & $6(0.4)$ & \\
\hline NMC-A30DS- $50{ }^{\circ} \mathrm{C}-\mathrm{SB}$ & - & $215 / 70$ & $0(1.5)$ & $88(80.6)$ & $12(0.4)$ & \\
\hline NMC-A60DS- $50{ }^{\circ} \mathrm{C}-\mathrm{SB}$ & - & $215 / 70$ & $0(1.5)$ & $83(80.6)$ & $17(0.4)$ & \\
\hline
\end{tabular}

AxDS, after $x$ days of storage $\left(x=15,30\right.$ or 60 ); NMC, native micellar casein; SB, standard bag; $T_{\text {in }} / T_{\text {out }}$, inlet temperature/outlet temperature; WB, watertight bag.

spray drying feed solutions, 2 drying temperatures for SMP and WMP and 2 homogenization passes for WMP. The author postulated that higher feed solids content would give rise to more viscous droplets, preventing the migration of components and redistribution at the surface. The authors goes onto describe now lactose concentration is stronger at higher temperatures, agreeing with Nijdam and Langrish (2006) proposal that the fat surface concentration is reduce by high temperatures in SMP and does not present an important influence in WMP. In addition any difference is noted with the increase of homogenization passes performed in WMP feeding solutions. Gaiani et al. (2010) observed an enrichment of the surface in lipids and proteins regardless of the spraydrying temperature (the powder was dried at 5 different outlet temperatures) or the formulation obtained by combinations of $\mathrm{Na}-$ tive micellar casein (NMC), Native whey isolate (NWI) and lactose. Furthermore, lipids enrichment is stronger in powders containing NWI than NMC and higher temperatures increase the protein-lactose surface content and reduce the surface fat content.

At pilot scale (Table 1b), Gaiani et al. (2006) produced and analyzed the surface of particles of NMC, and mixtures of NMC with protein ultrafiltrate or lactose, consequently surface particles was modified. The nature of the ingredient added was determinant in the surface modification. Later the same authors (Gaiani et al., 2007) studied the effect of storage in NMC powder at 20 and $50^{\circ} \mathrm{C}$, stoked in two different package (standard or watertight bags), the storage time was 15, 30 and 60 days each sample. Results revealed significant surface changes only after 60 days of storage, when powder is stocked in watertight bags. When powders are stored in standard bags, changes are registered after 30 days of storage. These results suggest that powder conservation is possible before 30 days of storage or more time if they are stocked in watertight bags. Temperature did not demonstrate an effect in surface composition modification.

At industrial scale (Table 1c), it was observed the surface composition of WMP, SMP, cream powder (CP) and whey protein concentrate (WPC) (Kim et al., 2002, 2005b). Later, the same author (Kim et al., 2009b), determined the effect of storage (6 months) for these powders, a migration of fat to the surface was systematically observed in all the powders. WMP, SMP and instant milk power (IMP), were collected in different points of the spray drying and fluidized bed processes (Kim et al., 2009a). Surface did not present strong changes in the structure according to the collection point, results suggest that surface characteristics are developed in drying and they are not modified in the subsequently steps. Murri-
eta-Pazos et al. (2012) compared the surface composition of WMP and SMP with the agglomerated milk powder versions: WMP granulated (WMPG) and SMP granulated (SMPG). A similar composition was observed between WMP and WMPG, the same effect was observed between SMP and SMPG. The agglomeration process consists in the addition of fine particles before the drying step, then the suspension of fines and milk is dried. The study demonstrates that this supplementary step does not change the surface composition. Fyfe et al. (2011) studied the effect of storage in milk proteins concentrate (MPC) after 14, 30, 60 and 90 days at 25 and $40{ }^{\circ} \mathrm{C}$. The powders were stocked in recipients with relative humilities at $44 \%, 66 \%$ and $84 \%$. No significant changes to the surface composition were observed.

Finally different solvents and treatments are applied to fatty dairy powders (WMP, WMPG, CP) in order to extract the surface free fat (Kim et al., 2002; Murrieta-Pazos et al., 2012). The efficiency of the technics can be observed after analysis of surface composition in "surface fat free" powders, then these powders were used to evaluate the evolution of functional properties.

Different mechanisms of powder surface formation were proposed and discussed from these results summarized in Tables $1 \mathrm{a}$, $1 \mathrm{~b}$ and $1 \mathrm{c}$, they all agrees with the formation of a fat surface, then the drying of the next layer forming a skin with a subsequently drying of the core.

Recently, this technique (surface composition by XPS) has been successfully applied to investigate links between particle surface chemical composition and particle functional properties.

\subsubsection{Reconstitution properties}

By comparing casein powders containing variable combinations of hygroscopic material (lactose and/or minerals), the presence of lactose at the powder surface calculated by the matrix model from XPS results, was found to improve the wetting properties (Gaiani et al., 2010). NMC was dried at 5 different temperatures. After addition of $30 \%$ of lactose to the formulation, lactose present in the surface increase (Table 1a) and wetting time was reduced from 932 to $639 \mathrm{~s}$ and 623 to $201 \mathrm{~s}$ respectively. The same study was performed for NWI. After addition of $30 \%$ of lactose in the formulation, the surface lactose also increases, showing a wetting time improvement from 1498 to $1085 \mathrm{~s}$ and 991 to $499 \mathrm{~s}$, respectively.

Surface fat cover seems to have a very important influence in the powder wetting properties. For the 25 powders studied (Gaiani et al., 2010), a direct correlation between fat surface content and wetting time was observed. For example, for the surfaces with 
Table 1c

Bulk composition and surface composition obtained from XPS and linear equation relating elemental components to lactose, protein and fat in milk powders and milk subproduct powders from industrial installations.

\begin{tabular}{|c|c|c|c|c|c|c|c|}
\hline $\begin{array}{l}\text { Powder } \\
\text { system }\end{array}$ & $\begin{array}{l}\text { Storage } \\
\text { conditions }\end{array}$ & $\begin{array}{l}\text { Solvent } \\
\text { nature }\end{array}$ & $\begin{array}{l}\text { Extraction } \\
\text { time }(\mathrm{h})\end{array}$ & $\begin{array}{l}\% \text { Of surface } \\
\text { lactose (bulk) }\end{array}$ & $\begin{array}{l}\% \text { Of surface } \\
\text { proteins (bulk) }\end{array}$ & $\begin{array}{l}\% \text { Of surface } \\
\text { fat (bulk) }\end{array}$ & References \\
\hline SMP & - & - & - & $36(51.0)$ & $46(36.0)$ & $18(1.0)$ & Kim et al. 2002 (2005b) \\
\hline WMP & - & - & - & $2(36.6)$ & $0(27.9)$ & $98(26.6)$ & \\
\hline $\mathrm{CP}$ & - & - & - & $1(12.3)$ & $0(11.5)$ & $99(71.5)$ & \\
\hline WPC & - & - & - & $6(7.4)$ & $41(80.4)$ & $53(5.6)$ & \\
\hline SMP & - & - & - & $27(50.0)$ & $61(34.0)$ & $12(1.0)$ & Shrestha et al. (2007) \\
\hline SMP & \multirow[t]{3}{*}{ After 6 months } & - & - & $36(51.0)$ & $44(36.0)$ & $20(1.0)$ & \multirow[t]{3}{*}{ Kim et al. (2009b) } \\
\hline WMP & & - & - & $1(36.6)$ & $0(27.9)$ & $99(26.6)$ & \\
\hline $\mathrm{CP}$ & & - & - & $0(12.3)$ & $0(11.5)$ & $100(71.5)$ & \\
\hline SMP-ASFB & - & - & - & $42^{*}(51.4)$ & $40^{*}(35.0)$ & $18^{*}(0.8)$ & \multirow[t]{8}{*}{ Kim et al. (2009a) } \\
\hline SMP-A2VFB & - & - & - & $40^{*}(51.4)$ & $42^{*}(35.0)$ & $18^{*}(0.8)$ & \\
\hline SMP-A3VFB & - & - & - & $42^{*}(51.4)$ & $39^{*}(35.0)$ & $19^{*}(0.8)$ & \\
\hline WMP-ASDC & - & - & - & $97^{*}(37.5)$ & $0^{*}(26.5)$ & $3^{* *}(26.8)$ & \\
\hline WMP-A3VFB & - & - & - & $98^{*}(37.5)$ & $0^{*}(26.5)$ & $2^{*}(26.8)$ & \\
\hline IWMP-ASDC & - & - & - & $98^{*}(36.1)$ & $0^{*}(28.0)$ & $2^{*}(26.8)$ & \\
\hline IWMP-A1VFB & - & - & - & $98^{*}(36.1)$ & $0^{*}(28.0)$ & $2^{*}(26.8)$ & \\
\hline IWMP-A2VFB & - & - & - & $98^{*}(36.1)$ & $0^{*}(28.0)$ & $2^{*}(26.8)$ & \\
\hline MPC & - & - & - & $1.8^{*}(4.8)$ & $68^{*}(84.7)$ & $30^{*}(1.5)$ & \multirow[t]{25}{*}{ Fyfe et al. (2011) } \\
\hline MPC-A14DS & \multirow{4}{*}{$20^{\circ} \mathrm{C}, 44 \mathrm{RH} \%$} & - & - & $1.6^{*}(4.8)$ & $67^{*}(84.7)$ & $32^{*}(1.5)$ & \\
\hline MPC-A30DS & & - & - & $1.2^{*}(4.8)$ & $69^{*}(84.7)$ & $30^{*}(1.5)$ & \\
\hline MPC-A60DS & & - & - & $1.6^{*}(4.8)$ & $68^{*}(84.7)$ & $30^{*}(1.5)$ & \\
\hline MPC-A90DS & & - & - & $3.6^{*}(4.8)$ & $68^{*}(84.7)$ & $28^{*}(1.5)$ & \\
\hline MPC-A14DS & \multirow[t]{4}{*}{$40^{\circ} \mathrm{C}, 44 \mathrm{RH} \%$} & - & - & $1.2^{* * *}(4.8)$ & $66^{*}(84.7)$ & $32^{*}(1.5)$ & \\
\hline MPC-A30DS & & - & - & $1.5^{*}(4.8)$ & $69^{*}(84.7)$ & $29^{*}(1.5)$ & \\
\hline MPC-A60DS & & - & - & $1.6^{*}(4.8)$ & $70^{*}(84.7)$ & $28^{*}(1.5)$ & \\
\hline MPC-A90DS & & - & - & $3.0^{*}(4.8)$ & $69^{*}(84.7)$ & $28^{*}(1.5)$ & \\
\hline MPC-A14DS & \multirow[t]{4}{*}{$20^{\circ} \mathrm{C}, 66 \mathrm{RH} \%$} & - & - & $3.0^{*}(4.8)$ & $67^{*}(84.7)$ & $30^{*}(1.5)$ & \\
\hline MPC-A30DS & & - & - & $1.8^{*}(4.8)$ & $67^{*}(84.7)$ & $32^{*}(1.5)$ & \\
\hline MPC-A60DS & & - & - & $2.2^{*}(4.8)$ & $67^{*}(84.7)$ & $30^{*}(1.5)$ & \\
\hline MPC-A90DS & & - & - & $3.2^{*}(4.8)$ & $67^{*}(84.7)$ & $29^{*}(1.5)$ & \\
\hline MPC-A14DS & \multirow[t]{4}{*}{$40{ }^{\circ} \mathrm{C}, 66 \mathrm{RH} \%$} & - & - & $1.5^{*}(4.8)$ & $65^{*}(84.7)$ & $33^{*}(1.5)$ & \\
\hline MPC-A30DS & & - & - & $2.2^{*}(4.8)$ & $67^{*}(84.7)$ & $30^{*}(1.5)$ & \\
\hline MPC-A60DS & & - & - & $1.0^{*}(4.8)$ & $69^{*}(84.7)$ & $30^{*}(1.5)$ & \\
\hline MPC-A90DS & & - & - & $3.5^{*}(4.8)$ & $67^{*}(84.7)$ & $29^{*}(1.5)$ & \\
\hline MPC-A14DS & \multirow[t]{4}{*}{$20^{\circ} \mathrm{C}, 84 \mathrm{RH} \%$} & - & - & $1.6^{*}(4.8)$ & $66^{*}(84.7)$ & $33^{*}(1.5)$ & \\
\hline MPC-A30DS & & - & - & $1.7^{*}(4.8)$ & $64^{*}(84.7)$ & $33^{*}(1.5)$ & \\
\hline MPC-A60DS & & - & - & $1.2^{*}(4.8)$ & $75^{*}(84.7)$ & $24^{*}(1.5)$ & \\
\hline MPC-A90DS & & - & - & $4.6^{*}(4.8)$ & $-^{*}(84.7)$ & $-^{*}(1.5)$ & \\
\hline MPC-A14DS & \multirow[t]{4}{*}{$40{ }^{\circ} \mathrm{C}-84 \mathrm{RH} \%$} & - & - & $1.8^{*}(4.8)$ & $67^{*}(84.7)$ & $33^{* * *}(1.5)$ & \\
\hline MPC-A30DS & & - & - & $2.2^{*}(4.8)$ & $64^{*}(84.7)$ & $30^{*}(1.5)$ & \\
\hline MPC-A60DS & & - & - & $2.2^{*}(4.8)$ & $66^{*}(84.7)$ & $30^{*}(1.5)$ & \\
\hline MPC-A90DS & & - & - & $3.5^{*}(4.8)$ & $67^{*}(84.7)$ & $29^{*}(1.5)$ & \\
\hline WMP & - & - & - & $0.5(52.0)$ & $6.2(37.1)$ & $93.3(1.4)$ & Murrieta-Pazos et al. (2012) \\
\hline AWMP & - & - & - & $1.3(36.7)$ & $7.5(26.2)$ & $91.2(27.3)$ & \\
\hline SMP & - & - & - & $30.9(52.0)$ & $45.1(37.1)$ & $22.8(1.4)$ & \\
\hline ASMP & - & - & - & $36.3(36.7)$ & $39.3(26.2)$ & $23.2(27.3)$ & \\
\hline SMP & - & Petroleum ether & 0.17 & $45(58)$ & $50(41)$ & $5(1)$ & Kim et al. (2002) \\
\hline & - & & 24 & $44(58)$ & $55(41)$ & $1(1)$ & \\
\hline & - & & 48 & $45(58)$ & $54(41)$ & $1(1)$ & \\
\hline WMP & - & Petroleum ether & 0.17 & $5(40)$ & $9(31)$ & $86(29)$ & \\
\hline & - & & 24 & $9(40)$ & $10(31)$ & $81(29)$ & \\
\hline & - & & 48 & $10(40)$ & $22(31)$ & $68(29)$ & \\
\hline $\mathrm{CP}$ & - & Petroleum ether & 0.17 & $23(13)$ & $10(12)$ & $67(75)$ & \\
\hline & - & & 24 & $24(13)$ & $12(12)$ & $64(75)$ & \\
\hline & - & & 48 & $26(13)$ & $15(12)$ & $59(75)$ & \\
\hline WPC & - & Petroleum ether & 0.17 & $7(8)$ & $92(86)$ & $1(6)$ & \\
\hline & - & & 24 & $9(8)$ & $90(86)$ & $1(6)$ & \\
\hline & - & & 48 & $9(8)$ & $90(86)$ & $1(6)$ & \\
\hline SMP & - & Hexane & 0.17 & $44(58)$ & $53(41)$ & $3(1)$ & \\
\hline & - & & 24 & $59(58)$ & $41(41)$ & $-(1)$ & \\
\hline & - & & 48 & $62(58)$ & $38(41)$ & $-(1)$ & \\
\hline WMP & - & Hexane & 0.17 & $3(40)$ & $24(31)$ & $54(29)$ & \\
\hline & - & & 24 & $63(40)$ & $18(31)$ & $19(29)$ & \\
\hline & - & & 48 & $67(40)$ & $19(31)$ & $14(29)$ & \\
\hline $\mathrm{CP}$ & - & Hexane & 0.17 & $4(13)$ & $0(12)$ & $96(75)$ & \\
\hline & - & & 24 & $4(13)$ & $0(12)$ & $96(75)$ & \\
\hline & - & & 48 & $5(13)$ & $0(12)$ & $95(75)$ & \\
\hline WPC & - & Hexane & 0.17 & $8(8)$ & $92(86)$ & $0(6)$ & \\
\hline & - & & 24 & $10(8)$ & $90(86)$ & $0(6)$ & \\
\hline & - & & 48 & $10(8)$ & $90(86)$ & $0(6)$ & \\
\hline
\end{tabular}


Table 1c (continued)

\begin{tabular}{lllllll}
\hline $\begin{array}{l}\text { Powder } \\
\text { system }\end{array}$ & $\begin{array}{l}\text { Storage } \\
\text { conditions }\end{array}$ & $\begin{array}{l}\text { Solvent } \\
\text { nature }\end{array}$ & $\begin{array}{l}\text { Extraction } \\
\text { time }(\mathrm{h})\end{array}$ & $\begin{array}{l}\text { \% Of surface } \\
\text { lactose (bulk) }\end{array}$ & $\begin{array}{l}\text { \% Of surface } \\
\text { proteins (bulk) }\end{array}$ & $\begin{array}{l}\% \text { Of surface } \\
\text { fat (bulk) }\end{array}$ \\
\hline WMP & - & Petroleum ether & $5 \times 0.83$ & $19.3(52.0)$ & $\begin{array}{l}\text { References } \\
18.1(37.1)\end{array}$ & $\begin{array}{l}62.5(1.4) \\
72.8(27.3)\end{array}$ \\
AWMP & - & Petroleum ether & $5 \times 0.83$ & $18.4(36.7)$ & $8.1(26.2)$ & 7 Murrieta-Pazos et al. (2012) \\
\hline
\end{tabular}

AxVFB, after $x$ vibrating fluidized bed $(x=1,2$ or 3); ASDC, after spray drying chamber; ASFB, after static fluidized bed; AWMP, agglomerated whole milk powder; ASMP, agglomerated skim milk powder; AxDS, after $x$ days of storage ( $x=14,30,60$ or 90$)$; CP, cream powder; IWMP, instant whole milk powder; MPC, milk protein concentrate; NWI, native whey isolate; RH, relative humidity; SMP, skim milk powder; $T_{\text {in }} / T_{\text {out }}$, inlet temperature/outlet temperature; T, Traces; WPC, whey protein concentrate; WMP, whole milk powder.

Values directly extracted from graphics.

higher fat content, values obtained by NWI dried at $70{ }^{\circ} \mathrm{C}(33.8 \%)$ gave a maximum registered wetting time of $1498 \mathrm{~s}$. The fastest wetting times were registered for NMC with addition in the formulation of $30 \%$ of lactose and spray dried at 110,130 and $150{ }^{\circ} \mathrm{C}$; this gave $0 \%$ surface fat. These results agreed with those obtained by Kim et al. (2002) studying WMP and CP. Here the wetting times for WMP and CP were higher than $900 \mathrm{~s}$, and after free fat extraction the wetting times were reduced to 35 and $100 \mathrm{~s}$ for WMP and $\mathrm{CP}$, respectively.

Lecithination of powders is a practice recurrent in the food powder industry that improves wetting and rheology of powders. Millqvist-Fureby and Smith (2007) added lecithin to SMP, WPC and lactose in order to adapt the method relating elemental analysis of XPS to surface composition of powders covered with lecithin. This adaptation was developed with a layer model indicating that lecithin would coat the whole particle surface. Surface composition for SMP + Lecithin, WPC + Lecithin and lactose + lecithin was $54.3 \%, 54.8 \%$ and $0 \%$ of proteins, $17.9 \%, 23.5 \%$ and $51.3 \%$ of lactose and $27.8 \%, 21.7 \%$ and $48.7 \%$ of lecithin respectively.

Authors attribute the low lecithin values to the thickness of the coverage. The lecithin layer thickness is estimated at approximately $2.5 \mathrm{~nm}$. This is thinner than the analysis depth $(10 \mathrm{~nm})$. From this value, estimation of the surface layer thickness for each powder was calculated: $1.6 \mathrm{~nm}$ for SMP + Lecithin, $0.8 \mathrm{~nm}$ for WPC + Lecithin and 1.9 for lactose + lecithin.

Another study related the wetting time of NMC powder with fat migration from the bulk to the surface during storage (Gaiani et al., 2007). Wetting values grew from $12 \mathrm{~s}$ in fresh powders to $35 \mathrm{~s}$ (watertight bag) and $73 \mathrm{~s}$ (standard bag) after 60 days storage at $20^{\circ} \mathrm{C}$. Results were more drastic when the powder is stored at $50{ }^{\circ} \mathrm{C}$ with $148 \mathrm{~s}$ (watertight bag) and $265 \mathrm{~s}$ (standard bag). This delay in the wetting time was attributed to a larger fat coverage.

For SMP the same phenomenon was observed. The fat surface coverage in fresh powder was determined at $18 \%$ and after 6 months of storage at room temperature $\left(10-30^{\circ} \mathrm{C}\right)$, the fat coverage shifted to $20 \%$. For WMP and CP, the fat surface coverage was important even for fresh powder (98\% and 99\%). However no significant changes were observed after 6 months storage (Kim et al., 2009c).

In order to improve the reconstituted powder properties, others studied the effect of processing parameters on the powder surface. High spray-drying temperatures (Gaiani et al., 2010), high solid content and homogenization (Kim et al., 2009c), appear to produce powders with less surface fat (Tables $1 \mathrm{a}, 1 \mathrm{~b}$ and $1 \mathrm{c}$ ) allowing shorter wetting times as demonstrated in the work of Gaiani et al. (2010).

The influence of the protein denaturation (mainly whey proteins) on components repartition in the dry particle was also studied by Millqvist-Fureby et al. (2001). A slight increase in surface fat was observed with the denaturation percentage whereas the lactose coverage was almost constant and the protein coverage decreased. The wetting time was augmented from 21 to $40.2 \mathrm{~s}$ for the corresponding degree of denaturation of $4 \%$ and $51 \%$ with a consequential increase in the surface fat content.

\subsubsection{Caking phenomena}

Caking is a prevalent situation that can cause problems in operation, equipment surfaces or product yield (Adhikari et al., 2001). Nijdam and Langrish (2006) related the degree of caking to the surface composition of milk powders presenting different fat contents. The results indicated that the degree of caking was high (>90\%) for powders containing between $5 \%$ and $30 \%$ of surface fat. On the other hand, the caking was importantly reduced $(<60 \%)$, when surface fat was less than $3 \%$. Here there appears to be a strong correlation between the caking ability of the powder and the fat surface coverage. Hartmann and Palzer (2011) studied caking kinetics of water-soluble amorphous powders. For these powders, the sinter bridges created in the powders were measured.

\subsubsection{Lipids oxidation}

Surface fat also indicates a susceptibly to oxidation (Kim et al., 2002). For example, an oxidation "signature" may be potentially observed by XPS. Kim et al. (2002) compared the oxygen peak of various dairy powders to detect an oxidation at the surface. After 2 days storage at $40^{\circ} \mathrm{C}$, the $\mathrm{O}_{1 \text { s }}$ peak had significantly changed in all the powders (SMP, WPC, WMP and CP), with the biggest increase (1.5\%) observed in the CP and the smallest observed in SMP.

\subsubsection{Flowability}

The flowability of a powder is an important property in handling and processing operations, such as storage, transportation, formulation, mixing, compression or packaging (Knowlton et al., 1994). Flowability is known to be highly dependent on particle size and distribution (Barbosa-Canovas et al. 1987), but also on surface chemical composition (Kim et al., 2005b). The angle of response was measured to reveal flow properties for different spray-dried powders: SMP, WMP, WPC and CP (Kim et al., 2005b). WMP and $\mathrm{CP}$ provided surfaces largely covered by fat. WPC gave a medium surface fat coverage and SMP a low surface fat coverage (Tables $1 \mathrm{a}, 1 \mathrm{~b}$ and $1 \mathrm{c})$. A regular flow was registered for skim milk powder $\left(85^{\circ}\right)$, the rest of the powders did not flow $\left(0^{\circ}\right)$. In order to find if flow difficulties came from lipid surfaces, free surface fat was extracted. Powders that did not flow before extraction flowed correctly after the procedure, presenting angles of response about $80^{\circ}$ (WMP), $60^{\circ}$ (CP) and $90^{\circ}$ (WPC). Kim et al. (2009c) also found some differences in flowability of skim milk powder after 6 months of storage increasing the contact angle from $85^{\circ}$ (fresh powder) to $90^{\circ}$.

\subsection{Use of XPS for non-dairy food powders}

The use of XPS in the field of vegetal powders was limited with accessibility onto to pour databases. XPS studies on starch permit elemental composition determination of the outer $5-10 \mathrm{~nm}$ of the granule surface. Russell et al. (1987) and Baldwin (2001) 
deduced the percentage of protein surface coverage from nitrogen peak areas. Granule surfaces of cereal starches contain between $1 \%$ and $2 \%$ nitrogen, whereas potato starch surfaces contain only $0.01 \%$ nitrogen. Using the nitrogen peak area technique the percentage of protein surface coverage was revealed as $4-12.5 \%$ for cereal starches and around $0.5 \%$ for potato starches. This protein content apparently varies according to the botanical source of the starch.

Saad et al. (2009) performed XPS on wheat flour before and after re-grinding and related the surface flour composition to water sorption properties. After decomposition of oxygen $\mathrm{O}_{1 \mathrm{~s}}(\mathrm{O}=\mathrm{C}, \mathrm{O}-\mathrm{C}$ and $\left.\mathrm{H}_{2} \mathrm{O}\right)$, carbon $\mathrm{C}_{1 \mathrm{~s}}(\mathrm{C}-(\mathrm{C}, \mathrm{H}), \mathrm{C}-(\mathrm{O}, \mathrm{N}), \mathrm{C}=\mathrm{O}$ and $\mathrm{O}-\mathrm{C}=\mathrm{O})$ and nitrogen $\mathrm{N}_{1 \mathrm{~s}}\left(\mathrm{C}-\mathrm{NH}\right.$ and $\left.\mathrm{C}-\mathrm{NH}_{3}\right)$ peaks, $\mathrm{C}_{1 \text { s }}$ peak appear induce a slight decrease of the $\mathrm{C}-(\mathrm{C}, \mathrm{H})$ bond from $61 \%$ in native flour to $60 \%, 59 \%$ and $57 \%$, respectively to first, second and thirst re-grinding passes. Concurrently the total of $\mathrm{C}-\mathrm{O}$ functions $(\mathrm{C}-(\mathrm{O}, \mathrm{N}), \mathrm{C}=\mathrm{O}$ and $\mathrm{O}-\mathrm{C}=\mathrm{O}$ ) increased. From the $\mathrm{O}_{1 \mathrm{~s}}$ peaks, the $\mathrm{O}=\mathrm{C}$ functions increased significantly whereas the $\mathrm{O}-\mathrm{C}$ functions decreased from $82 \%$ in native flour to $77.5,76.9$ and 75.2 , respectively to first, second and thirst re-grinding passes.

These results reflect a decrease in the number of hydrophobic bonds and a decrease in the number of hydrophilic bonds. The authors attribute this behavior to physical changes induced by re-grinding resulting in starch granule rupture.

The matrix formula developed for dairy powders (Fäldt, 1995) was derived for wheat powders (Saad et al., 2011a). Native flours as well as flours reconstituted from pure components were analyzed in order to validate the method. Surface of reconstituted flours was calculated. For example, for a mix of $90 \%$ starch-10\% protein, the surface composition resulted between $87.4 \%$ and $90.6 \%$ of starch and between $12.9 \%$ and $10.3 \%$ of proteins, depending on the calculus method. These values were consequent with the mixture composition. A very different result was obtained for native powders, 5 native flours were analyzed: wheat flour standard (F1), peeled flour of crusty wheat variety (F2), pearled flour of crusty wheat variety (F3), peeled flour of tiger wheat variety (F4) and pearled flour of tiger wheat variety (F5). Surface composition obtained for flours F1, F2, F3, F4 and F5 was: 1.7, 1.2, -6.5, $-1,3$ and $-5.7 \%$ of starch, $54.2 \%, 53.8 \%, 70.5 \%, 85.6 \%$ and $66.5 \%$ of protein and $44.5 \%, 45.3 \%, 36.6 \%, 28.9 \%$ and $39.6 \%$ of lipids, respectively. The composition of the native flour presents an over-representation of lipids and proteins, compared with the bulk composition (81.3\% starch, $12.9 \%$ protein, $2.3 \%$ lipids). After comparison of native and reconstituted flours, native powders were more complex materials with a heterogeneous distribution of the components. Authors concluded that surface composition is not a simple transposition of the bulk composition suggesting some mask interactions between the components. The lack of references for cereal products makes difficult to conclude on the reliability of this method applied to characterization of surface cereal products (Saad et al., 2011a). The surface of wheat flour fractions was also studied (Saad et al., 2011a), the same technique was used to determine the surface composition of fractions. When analyzing fractions, the protein content decreases from $51.9 \%$ to $43.5 \%$ and the lipid content increases from $46.7 \%$ to $51.1 \%$. With the augmentation of the particle size, a clearest tendency is observed in ground flour sieved decreasing from $54.8 \%$ to $20.9 \%$ of protein and $46.3 \%$ to $63.4 \%$ of lipids with the size particle augmentation. In both cases, the starch content was relatively constant (Saad et al., 2011a).

The use of XPS in the field of other food powder is infrequent. Stevens and Schroeder (2009) performed quantitative analysis of saccharides by XPS. They presented the spectra of various carbohydrates. The accuracy of the analysis permits the distinction between mono-, di-, and polysaccharides. Indeed, chemical shifts of the $\mathrm{C}-\mathrm{O}$ and $\mathrm{O}-\mathrm{C}-\mathrm{O}$ groups increase on moving from monosaccharides to disaccharides to polysaccharides, actually the rates of $\mathrm{Al}$
K $\alpha$ X-ray-induced degradation are significantly different, specifically the $\mathrm{O} / \mathrm{C}$ decrease and increase in the peaks at 285 and $289.1 \mathrm{eV}$. These authors also found a relationship between the caramelization tendency and time of exposure to XPS radiation. The database developed is now a useful tool for surface carbohydrate analysis.

Vega et al. (2005) adapted the matrix formula (Fäldt 1995) for spray dried ice cream mixes, different formulations were tested. Ice cream spray dried powders observed the same over-representation of the fat at the surface (between $81 \%$ and $96 \%$ ) in comparison with bulk composition (between $19.1 \%$ and $44.9 \%$ of fat content), powders without emulsifiers and containing casein reduced surface fat (from $85 \%$ to $78 \%$ ) at expense of higher protein coverage $(6-11 \%)$, powers without emulsifiers not containing casein also reduced fat cover (from $81 \%$ to $73 \%$ ) exchanging this deficit by a gain in protein cover (from 8 to $15 \%$ ).

Rouxhet et al. (2008) analyzed cake ingredients; the authors propose an elaborated model to relate atomic composition to biochemical molecules. In order to achieve this propose they extracted information on chemical functions and refine the results expression in terms of molecular constituents. This model make possible distinguish among proteins, carbohydrates, phospholipids (PL) and neutral lipids (NL) in flour, eggs white, egg yolk and whole egg powders. The results agree with those obtained from the matrix model (Fäldt, 1995), surface molecule distribution is different from bulk composition. Results illustrating similitudes between the both methods are obtained for flour. This powder presents concentrations of PL and NL fewer than $2 \%$ in bulk composition in contrast to the surface with approximately $10 \%$ and $30 \%$ of PL and NL, respectively. Even when results are consequent with others publications, this method is more detailed and permits to obtain finest information about the surface by discriminating different molecules of the same family (lipids).

\subsection{Interesting complementary technique}

The combination of time of flight secondary ion mass spectrometry (ToF SIMS) and XPS has proved to be a valuable tool for the analysis of surfaces. Until now, this combination had never been done for food powders. The ToF-SIMS uses a pulsed primary ion beam to desorb and ionize species from a sample surface. The resulting secondary ions are accelerated into a mass spectrometer and are then mass analyzed by measuring their time-of-flight from the sample surface to the detector. The application of ToF-SIMS in food analysis has been explored only very recently. For example, this method has been applied with success to analyze pesticides on the surface of olives (Focardi et al., 2006), the principal component presenting the strongest variance (90.3\%) after analysis of 51 samples, was used to determine differences on the surface samples. The study shown signals at $m / z=31\left(\mathrm{CH}_{3} \mathrm{O}^{+}\right)$and $m / z=147$ $\left(\mathrm{C}_{6} \mathrm{H}_{14} \mathrm{NOP}^{+}\right.$or $\left.\mathrm{C}_{6} \mathrm{H}_{13} \mathrm{NOS}^{+}\right)$with higher intensities in native olives $\left(1.12 \times 10^{-4}, 2.93 \times 10^{-5}\right.$, respectively) than olives covered with pesticide $\left(4.23 \times 10^{-4}, 2.42 \times 10^{-4}\right.$, respectively). Cliff et al. (2003), adapted the technique to monitoring and imaging clofazamine with dominant peaks $m / z 184\left[\left(\mathrm{CH}_{3}\right)_{3} \mathrm{NCH}_{2} \mathrm{PO}_{4} \mathrm{H}_{2}\right]$ on the surface of yeast cells in the frozen-hydrated state. They demonstrated the absence of clofazamine within molecular information from a cell fractured in order to reveal the cell ultrastructure. In the therapeutic field, Grenha et al. (2007) characterized the surface and the internal structure of microsphere containing chitosan and mannitol. It was possible to investigate the repartition of the components in the particle surface by obtaining the characteristics peaks of each component $\mathrm{m} / \mathrm{z} 193\left(\mathrm{CH}_{19} \mathrm{P}_{2} \mathrm{~N}_{6} \mathrm{O}\right), \mathrm{m} / \mathrm{z} 249$ $\left(\mathrm{C}_{10} \mathrm{H}_{18} \mathrm{PO}_{5}\right)$, and $\mathrm{m} / z 281\left(\mathrm{C}_{4} \mathrm{H}_{21} \mathrm{~N}_{14} \mathrm{O}\right)$, chitosan nanoparticles being successfully encapsulated in mannitol microspheres. All these works have demonstrated the power of ToF-SIMS spectral 


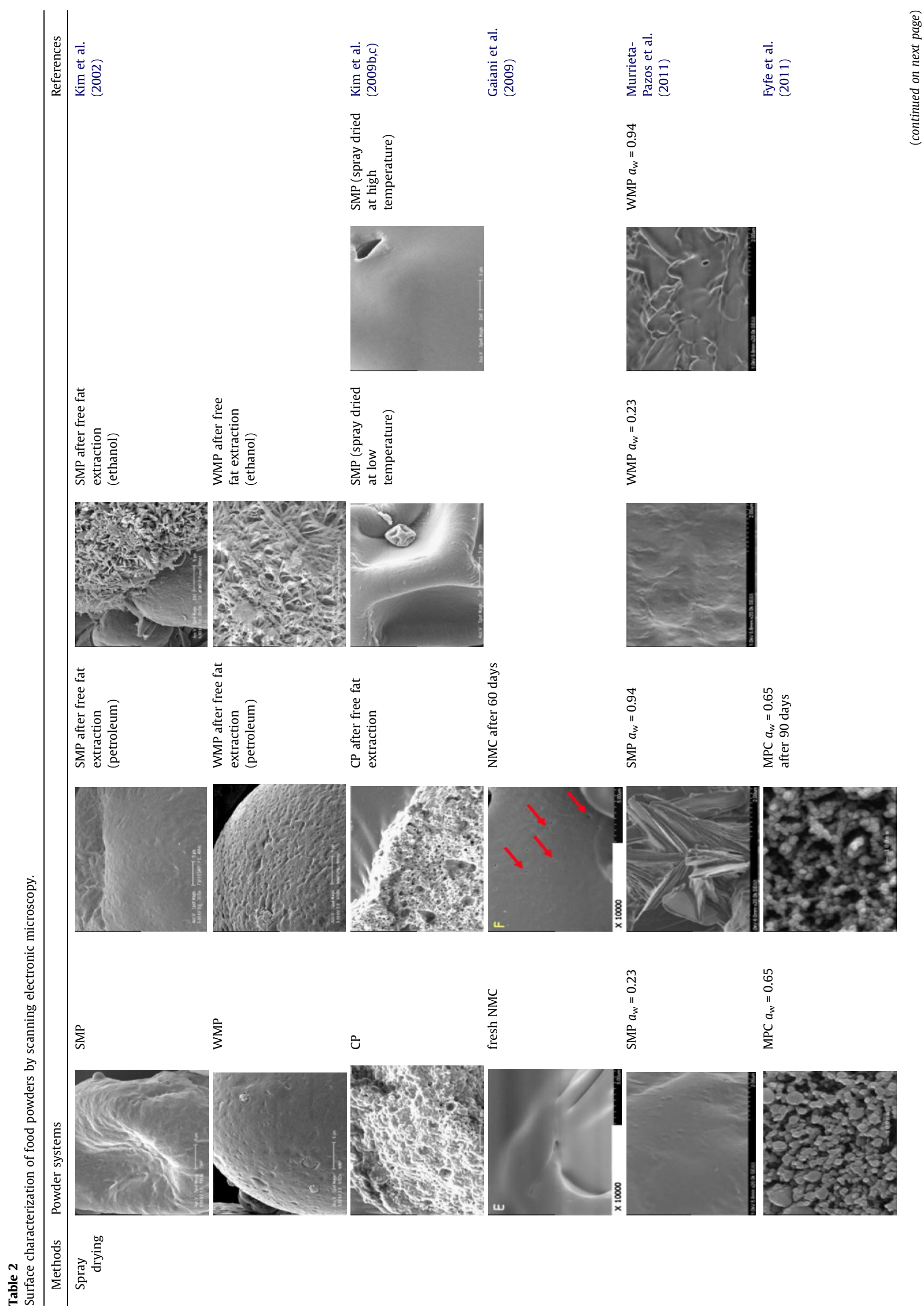




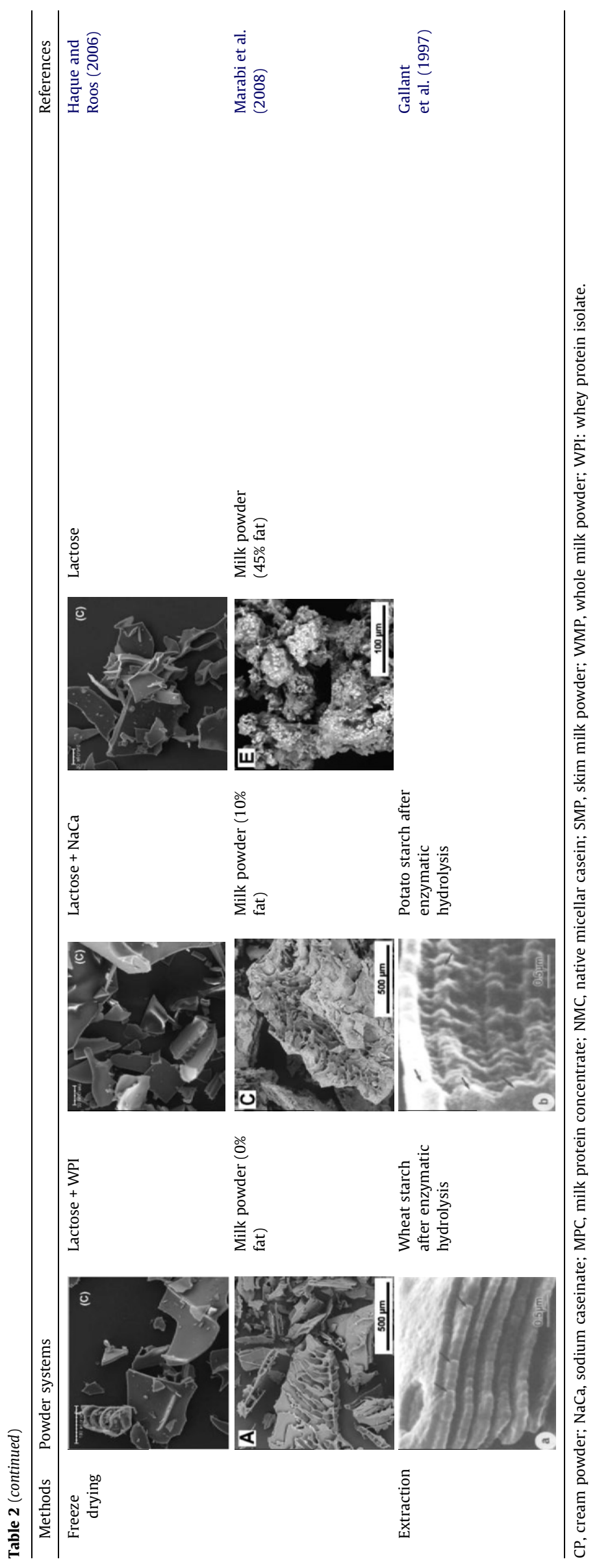

analysis and chemical imaging for the study of food and may be an interesting tool for food powders.

\section{Microscopy techniques making surface characterization possible}

\subsection{Electron microscopy techniques}

\subsubsection{Classical SEM characterization}

SEM apparatus uses a beam of electrons instead of light to form an image. In some cases, it may be necessary to cover the powders with a thin layer of carbon or gold to give it conductive properties. In food powders, SEM images could detail the particle shape and surface aspect. Powders suprastructure and organization have been widely studied in milk (McKenna et al., 1999) and milkwheat flour mixtures (Al Mahdi et al., 2006). For dairy powders, surface dents have been widely registered (Gaiani et al., 2006; Millqvist-Fureby and Smith, 2007; Kim et al., 2009b; Haque and Roos, 2006). Lactose mixtures and milk models obtained by freeze-drying (Marabi et al., 2008) (Table 2), presents the same structure described by Haque and Roos (2006) (Table 2), who also noted more bright surfaces in higher surface fat content powders. Different spray dried milk powders (skim milk, whole milk, cream and whey protein concentrate) were treated with petroleum ether and ethanol in order to extract surface free fat (Kim et al., 2002). The SEM images obtained from powders before extraction show smooth surfaces and clearly dented surfaces after ethanol extraction; a less affected surface was obtained with petroleum ether, (Table 2). Kim et al. (2009c) obtained milk powders at two spraydrying temperatures $\left(145 / 85\right.$ and $\left.205 / 105^{\circ} \mathrm{C}\right)$. More spherical particles and smoother surfaces were obtained at the higher temperature (Table 2). It was also observed that particles bigger than $90 \mu \mathrm{m}$ are agglomerates. SEM was also used to characterize powder surfaces during storage, thus Gaiani et al. (2009) noticed some pores at the surface of casein powders, (Table 2). Cross section analyses of milk and cream powders (Table 2) were also performed after free fat extraction (Kim et al. 2009b). Here the authors deduced some capillary properties that may interact in the migration of fat into the surface. Murrieta-Pazos et al. (2011) observed the evolution of lactose crystals formed at the surface of WMP and SMP conditioned at different relative humidities (Table 2).

Jenni (2007) observed a change in the shape and the surface aspect of wheat flour particles as a function of their size; the particles became less and less rounded and more and more rough as size increased. Partial dissolution of particles surface was observed in MPC stored at 65\% RH during 14 and 30 days (Table 2) by Fyfe et al. (2011). The starch granule has been also widely studied. Fannon et al. (1993) observed pores at the surface of starch granules of potato, corn and wheat deducing the formation of interior channels in the structure. Later, Gallant et al. (1997), observed starch from different botanical sources, meanly wheat and potato (Table 2). These particles were characterized as a golf ball shape, where nodules correspond to amylopectin-based blocklets suspended in an amylose-based supporting matrix.

\subsubsection{Interesting complementary methods}

Recently, SEM images were sometimes combined with energy dispersive X-ray spectroscopy (EDX) analyses. The EDX analysis system works as an integrated feature of a SEM apparatus and cannot operate on its own. Its characterization capabilities are due in large to the fundamental principle that each element has a unique atomic structure, thus X-ray energy emitted by the atoms after excitation with an electron ray is characteristic of each element's atomic structure. Hence one element can be identified uniquely from one another. To stimulate the emission of 
Table 3

Surface characterization of food powders by atomic force microscopy.

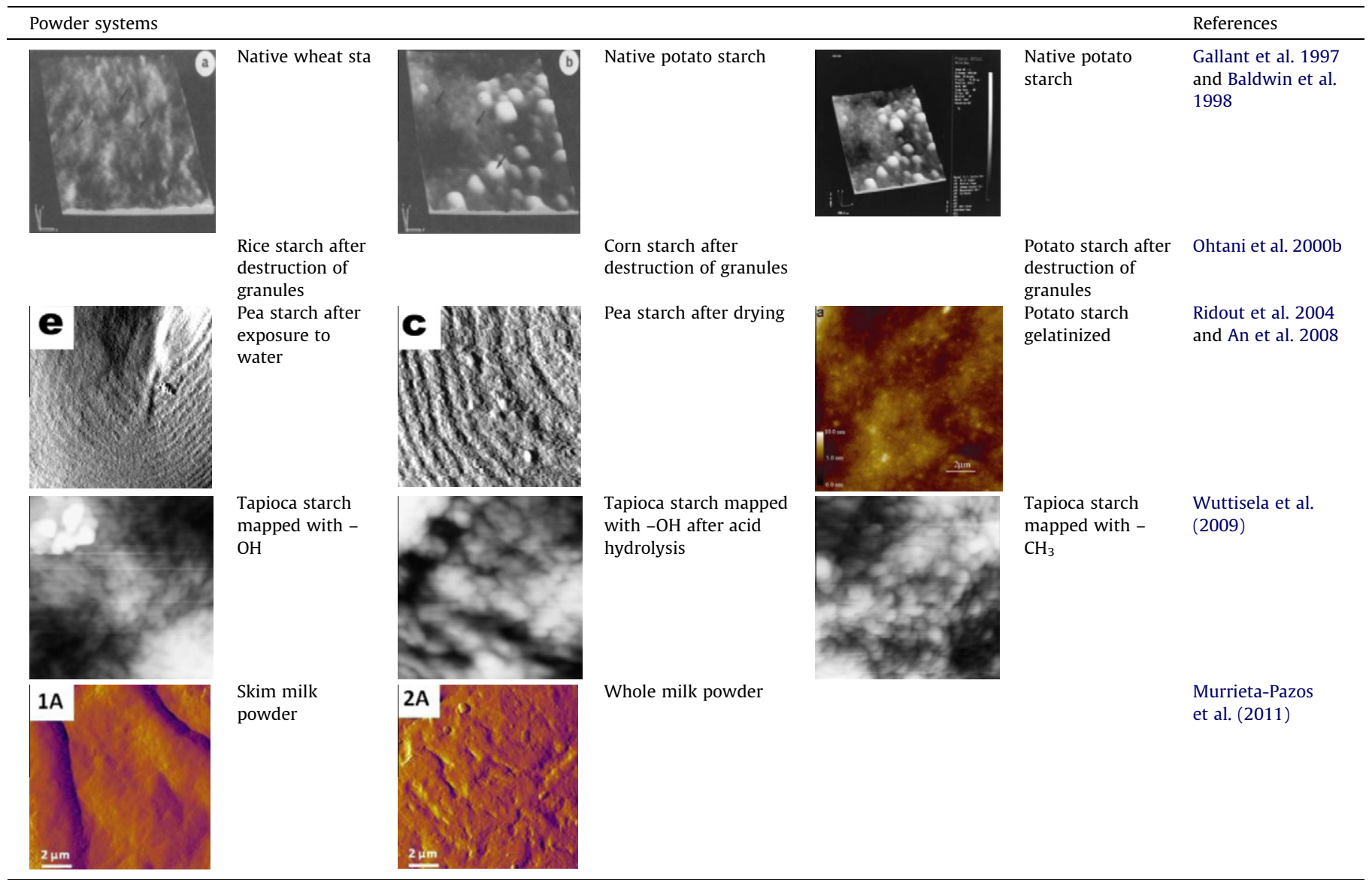

characteristic X-rays from a specimen, a high-energy beam of charged particles is focused into the sample. The output of an EDX analysis is an EDX spectrum, which is a plot of how frequently an X-ray is received for each energy level. The higher a peak in a spectrum, the more concentrated the element is in the sample. This technique was used for identifying the elemental composition of the sample, or an area of interest thereof.

EDX has been used on vegetal material and food extracts. For example, EDX spectra showed mineral nutrients ( $\mathrm{P}, \mathrm{K}$ and $\mathrm{Mg}$ ) stored in different tissues of quinoa seeds (Prego et al., 1998). Other authors analyzed some protein bodies in tissues of different rice grains by this technique and observed some micronutrients ( $\mathrm{Fe}, \mathrm{Mn}, \mathrm{Zn}$ and $\mathrm{Cu}$ ) and macronutrients ( $\mathrm{P}, \mathrm{Mg}$ and $\mathrm{K}$ ) in specific rice genotypes (Prom-u-thai et al., 2008). Recently, this technique has also been used for the detection of irradiation treatment on basmati rice by the analysis of minerals extracts (Sanyal et al., 2009). In the field of food powder, Murrieta-Pazos et al. (2011, 2012), adapted the matrix model in XPS (Fäldt, 1995) in this case using EDX data to investigate the chemical composition of dairy powders at a depth of approximately $1 \mu \mathrm{m}$. Surface composition was calculated for WMP and SMP. Protein, lactose and lipids content were respectively for $\mathrm{WMP}=34 \%, 16.8 \%, 46.4 \%$ and for SMP $=25.8 \%, 13.7 \%, 58.6 \%$ (Murrieta-Pazos et al., 2011). The same technique was performed to characterize the surface of granulated milk powders (GWMP and GSMP). Protein, lactose and lipids content was for $\mathrm{GWMP}=21.3 \%, 11.9 \%, 65.4 \%$ and for $\mathrm{GSMP}=7.5 \%$, $1.3 \%, 91.2 \%$, respectively. Another analyze was performed for whole milk particles (WMP and GWMP), after extraction of the free fat at the surface. The surface composition of protein, lactose and lipids obtained was WMP $=30.0 \%, 11.3 \%, 55.5 \%$ and GWMP $=31.3 \%$,
$13.1 \%, 52.3 \%$, respectively. By comparing these surface composition with those obtained by XPS (Table 1c), an interesting gradient model of a milk powder particle was proposed (Murrieta-Pazos et al., 2012).

\subsection{Atomic force microscopy (AFM)}

In food science, application of the AFM is quite recent and mostly concerns the study of the structures of biopolymers (mostly polysaccharides including carrageenan, cellulose, pectin, xanthan) as film deposition onto a surface (Iijima et al., 2007; Kirby et al., 2008; Funami, 2010; Olivares et al., 2010; Lukasiewicz et al., 2007). As example, a model to explain the mechanism was deduced from the observation of the pectin structure during acid hydrolysis (Round et al., 2010). AFM was also used for direct imaging of the inner surface topography of food objects like whole grains and starch granules.

In food powders, AFM can be used to investigate the surface topology of different botanical sources of starch granules at the nanoscale. Some examples are: wheat (Baldwin, 1995; Baldwin et al., 1998; Gallant et al., 1997), pea (Ridout et al., 2004) and also rice (Ohtani et al., 2000a). Some of these examples are illustrated in Table 3. By comparing the difference between the highest and lowest points on a granule surface (measured at a scan size of $1000 \mathrm{~nm}^{2}$ ), Baldwin et al. (1998) reveals a flatter surface of Riband wheat starch compared to potato starch (Table 3 ). Ohtani et al. (2000b) observed starch by different methods of sample preparation as microtome, enzymatic digestion and physical destruction of starch granules, from five different botanical sources (corn, potato, rice, sweet potato and wheat). Images revealed different 
Table 4

Characterization of food powders by transmission electron microscopy (TEM).

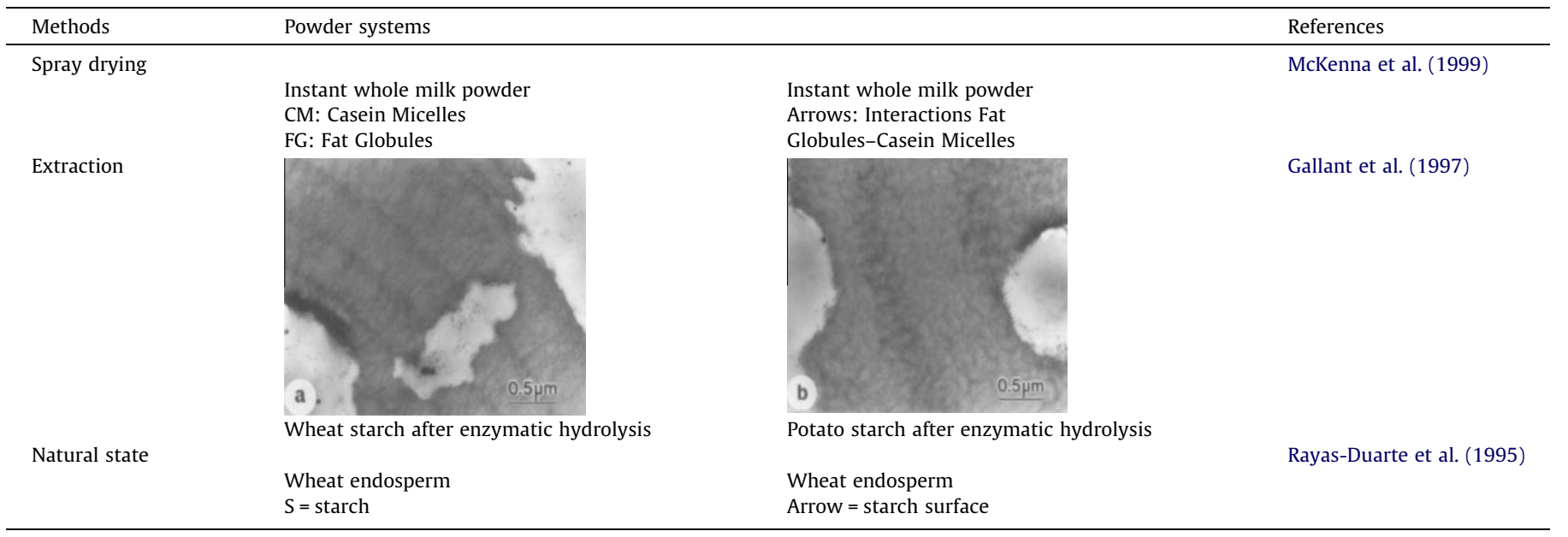

surface roughness depending on the botanical source, but supported a blocklet starch model. The structure of the starch granules after hydration have been studied and showed a banded-ring structure alternating amorphous and crystalline rings (Parker et al., 2008; Gunning et al., 2010). The gelatinization of starch (from different sources, pure or blended with other biopolymers, during heating) was also observed (An et al., 2008; Funami et al., 2008; Quiroga and Bergenståhl, 2007), some examples are presented in Table 3. Some interesting scanning chemical force microscopic investigations have been reported recently, native and hydrolyzed tapioca starch have been imaged with functionalized $-\mathrm{OH}$ and $-\mathrm{CH}_{3}$ tip probes in order to study the relationship of the surface structure and the amylose/amylopectin ratio (Table 3). However the differences in the chemical domain of the starch were not determined by topographic images (Wuttisela et al., 2009).

The majority of food particle powders are multi-component and rough. In the studies reported in the literature, the food material samples are specially prepared for AFM imaging by either embedding into a resin, slicing, powdering or centrifuging in a suspension to then deposit or fix the sample onto a mica plate. To use the AFM techniques to image the surface of food particles and study their topology is still a challenge. Until now, AFM was rarely tested on flours (Jenni, 2007) or dairy powders (Murrieta-Pazos et al., 2011) and/or others food powders than starch (Waduge et al., 2010; Tomoaia-Cotisel et al., 2010). Recently, Murrieta-Pazos et al. (2011) demonstrated the precision of the technique to characterize the surface of two dairy powders presenting low and high fat surface coverage (Table 3). AFM images were in agreement with those obtained by SEM, revealing a flat surface for skim milk powder (SMP) and a rough surface for whole milk powder (WMP). In addition, the average surface roughness was determined and was respectively found around $306 \mathrm{~nm}$ for SMP and $146 \mathrm{~nm}$ for WMP for a definite surface area $(10 \times 10 \mu \mathrm{m})$. AFM was also recently used to study the structure of MPC particles as a function of the storage in reconstituted milk (fresh and after ageing 30 days at $25^{\circ} \mathrm{C}$ and 65\% RH) (Fyfe et al., 2011). The AFM measurements permit to conclude that the surface modification of the aged MPC and the increase of the surface hydrophobicity contribute to the decrease of the MPC solubility during storage.

\subsection{Transmission electron microscopy (TEM)}

In TEM, an image is formed from a beam of electrons transmitted through an ultra thin specimen and consequently forms an image at the receiving device. The beam of electrons interacts with the specimen as it passes through. The application in food powders is not very extensive. Nevertheless, specific details about protein-protein and protein-fat interactions can be observed in milk powder samples (Vignolles et al., 2009). The microstructure of four commercial whole milk powders and their insoluble residuals were observed. Differences were observed depending on the processing conditions (McKenna et al., 1999; Qi, 2007).

TEM has permitted the understanding of the suprastructure of the starch granules. These studies started with Whistler and Turner (1955). "Blockets" of granules were later observed in the starch surface structure (Baldwin et al., 1997), and more recently, a technique was performed that oxidized the surface of amorphous regions in order to attach silver particles. The silver helps highlight the starch superstructure (Table 4) and so a model has been developed (Gallant et al., 1997).

Rayas-Duarte et al. (1995) used gold-labeling to detect a specific polypeptide by TEM, both in the surface and inside the starch granule in wheat endosperm.

\subsection{Confocal laser scanning microscopy (CLSM)}

Recently, CLSM was shown to be a helpful tool for internal microparticles characterization. CLSM enables the production of 3-dimensional optical plan images. It can provide information about particle morphology and the location of fat at the surface of whole milk particles (McKenna, 1997). The work of McKenna et al. (1999) for different commercial whole milk powders, was complemented by CLSM observations of differences in fat droplet size and distribution across the surface under different process conditions. CLSM was also performed on high-fat milk powders after a 6 month storage period, with and without homogenization (Table 5) by Vignolles et al. (2009). Differences in fat droplet size were also associated to the process conditions. The distribution of fat within and on the milk powder was also studied by Kim et al. (2002), results are presented in Table 5. Chanvrier et al. (2005) observed the protein structure in corn flour (Table 5). The influence of drying temperatures was investigated by Paramita et al. (2010) on microencapsulated limonene. The increase of the feed temperature increased the wall thickness and decreased the diameter of hollow particles. This is found favorable to avoid flavor release and to resist the penetration of both oxygen and water from the surrounding environment. Paramita et al. (2010) have also employed the CLSM technique for studying the morphology of spray-dried microcapsules. 
Table 5

Characterization of food powders by confocal laser scanning microscopy (CLSM).

\begin{tabular}{|c|c|c|c|c|c|}
\hline Methods & Powder systems & & & & References \\
\hline $\begin{array}{l}\text { Spray } \\
\text { drying }\end{array}$ & & $\begin{array}{l}\text { Instant whole milk } \\
\text { powder } \\
\text { Whole milk powder }\end{array}$ & & Instant whole milk powder & $\begin{array}{l}\text { McKenna et al. } \\
\text { (1999) } \\
\text { Kim et al. (2002 }\end{array}$ \\
\hline & & $\begin{array}{l}\text { Milk model with low free } \\
\text { fat }\end{array}$ & (D) & $\begin{array}{l}\text { Milk model with low free fat after free fat } \\
\text { extraction }\end{array}$ & $\begin{array}{l}\text { Vignolles et al. } \\
\text { (2009) }\end{array}$ \\
\hline & (B) & $\begin{array}{l}\text { Milk model with high free } \\
\text { fat }\end{array}$ & (E) & $\begin{array}{l}\text { Milk model with high free fat after free fat } \\
\text { extraction }\end{array}$ & \\
\hline Milling & & Proteins in corn flour & & & $\begin{array}{l}\text { Chanvrier et al. } \\
2005\end{array}$ \\
\hline
\end{tabular}

\section{Laser diffraction and dynamic image analysis}

Until recent years, shape analyses were performed by image processing techniques obtained by CLSM and/or SEM (Du and Sun, 2004). Nowadays, laser diffraction systems coupled with image processing have been developed and permit on line measuring of size and shape in a very high number of particles. A great number of qualitative terms may be used to give some indication of particle shape (Saad et al., 2011b). For example, the circularity or sphericity is defined as the ratio of the perimeter or the silhouette and the circumference of a disk that has de same area as the silhouette and the convexity is the ratio of the value obtained by projecting a particle area filling concave zones and the real area. This describes the compactness of a particle (Hentschel and Page, 2003).

Saad et al. (2011b) developed a quantitative method to evaluate shape factors (elongation, circularity, compactness and convexity) of wheat powder particles. The powders studied were, Native Flour, Sieved Flour $<125 \mu \mathrm{m}, 125-160 \mu \mathrm{m}$ and $>160 \mu \mathrm{m}$, Native semolina and Semolina Sieved $<315 \mu \mathrm{m}$ and $>315 \mu \mathrm{m}$. Wheat particle display values of elongation between 2.04 and 2.11 , circularity from 1.13 to 1.17 , compactness between 0.690 and 0.707 and finally convexity from 0.902 to 0.873 .

The wetting behavior of a solid particle may be influenced by the particle size. The wettability time was systematically shorter (88-115 s) for large $(\sim 400 \mu \mathrm{m})$ particles in the case of casein powders (Gaiani et al., 2005). Indeed, faster wetting (4.1 s studying $4 \mathrm{~g}$ of sieved skim milk powder) is often recorded with large particles $(>1000 \mu \mathrm{m}$ ) doe to the formation of large pores, high porosity and small contact angles between the powder surface and the penetrating water (Freudig et al., 1999). Very little work has been carried out for food powders on particle morphology (Gaiani et al., 2011b; Perea et al., 2009) whereas the literature was very furnished for minerals powders (Ulusoy, 2008; Chau et al., 2009). Nevertheless, Perea et al. (2009) found some relationships between the morphology of milk powder agglomerates and their rehydration properties. An increase of the solubility and the wettability was related with an increase of the particle compactness and shape factor. The study of Gaiani et al. (2011b) showed, for the first time, a correlation between powder rehydration properties and particles shape, in addition to the particle size and color (mainly related to chemical composition). The sphericity was the shape parameter demonstrating a stronger influence in rehydration properties, sphericity values were registered between 0.5 and 0.9 for dairy powders (NMC, NWI, SMP, WMP and Semi-SMP), small particles presenting high sphericities values $(\sim 0.9)$ obtained lower wetting times, SMP $=1750 \mathrm{~s}$, Semi-SMP $=1650 \mathrm{~s}$, NMC $=2500 \mathrm{~s}$. Furthermore, a regression model was developed to replace time-consuming measurements for dispersibility and solubility.

\section{Dynamic vapor sorption (DVS)}

The DVS apparatus provides fully automated, rapid and accurate measurements of gravimetric moisture uptake in solid materials at a wide temperature range using dynamic environment control and ultra-sensitive recording microbalance. Sorption isotherms were performed for casein powder during storage by Gaiani et al. (2009). By applying the model of Guggenheim-AndersonBoer (GAB), after 60 days of storage, a decrease of the monolayer capacity was registered from 0.0632 to $0.0617 \mathrm{~kg} / \mathrm{kg}$ at $20^{\circ} \mathrm{C}$ and from 0.0632 to $0.0524 \mathrm{~kg} / \mathrm{kg}$ at $50^{\circ} \mathrm{C}$. This decrease in the water affinity was related to the surface fat increases during storage. It was hypothesized that a layer of fat may progressively cover the 
surface making it more hydrophobic, the appearance of this fat layer was confirmed by XPS (Tables 1a, 1b and 1c). Wheat flour isotherms were also registered by Saad et al. (2009). Isotherms were fitted to GAB model, the values shown a slightly increase in the monolayer capacity, from values obtained in native flour $(0.085 \mathrm{~kg} / \mathrm{kg})$ to those registered after first pass re-grinding $(0.084 \mathrm{~kg} / \mathrm{kg})$, second pass re-grinding $(0.085 \mathrm{~kg} / \mathrm{kg})$ and thirst pass re-grinding $(0.0864 \mathrm{~kg} / \mathrm{kg})$, even when XPS presents a decrease in the number of hydrophobic bonds in contrast to hydrophilic bonds. Authors attributed the higher water affinity to a starch granule rupture caused by the re-grinding process. Mathlouthi and Rogé (2003) correlated the water vapor adsorption isotherm to the caking and flowability of sieved and/or pulverized sucrose, studding from amorphous and/or crystalline $(\mathrm{RH}>86 \%)$ forms. Flowability measured as friability angle was registered from $35-55^{\circ}$ at $\mathrm{HR}=30 \%$ to $90^{\circ}$ at $\mathrm{HR}=90 \%$ for all the sizes. The caking of crystalline forms does not allow to decaking the powder because of an agglomeration phenomena. Murrieta-Pazos et al. (2011) related data obtained from the sorption isotherm to the powder surface composition (EDX, AFM and XPS). The curves of diffusivity were directly correlated to the chemical state of lactose crystallized (HR $>54 \%$ ) or amorphous ( $\mathrm{HR}<54 \%$ ), during water uptake and its localization at the surface. The protein, lactose and lipids composition registered in the first micrometers (by EDX at $\sim 1 \mu \mathrm{m}$ ) was $\mathrm{SMP}=34.0,16.8$ and 46.4, respectively and $\mathrm{WMP}=25.8,13.7$ and 58.6 , respectively, the composition of the first nanometers (by XPS at $\sim 10 \mathrm{~nm}$ ) is shown in Table $1 \mathrm{c}$.

The DVS method could not give direct information about the surface but may be used to obtain the following data: monolayer capacity, water binding energy, specific surface area. These data were in turn related to the particle surface characteristics.

\section{Surface chemical extraction techniques}

Different extraction techniques have been developed to obtain surface fat from dairy powders Table 6. Vignolles et al. (2009) enhanced one technique by varying the solvent hydrophobicity, the number of extractions, the solvent/powder ratio, the agitation mode and intensity, and also the extraction time. Kim et al. (2009a) precisely described a procedure to selectively collect surface free fat, inner free fat, encapsulated fat and total fat.

After fat extraction, it may be of interest to obtain information about the extracted fractions. DSC and high performance liquid chromatography (HPLC) are the most used in order to compare total fat with surface fat properties.

DSC is one of the most widely used thermal analytical techniques in food research (Farkas and Mohácsi-Farkas, 1996). Vignolles et al. (2009) adapted protocols of DSC to measure the thermal profiles of fat in situ directly in powder samples, and in anhydrous bulk fat extracted from the powders. In a low free fat dairy powder, i.e. less than $5 \%$ of the total fat, the crystallization profile of fat in the powder after free fat extraction had a second exothermic peak which enthalpy was higher than in the powder before free fat extraction.

The crystallization curves obtained were different and attributed to a difference in fat suprastructure and fat composition. On cooling, different melting profiles were also observed and attributed to different fatty acid organization in total and free fat. Kim et al. (2005a), Murrieta-Pazos et al. (2012) and Vega et al. (2005) studied dairy powders and ice cream mixture powders and they did not found differences in the melting profiles of free fat and encapsulated fat. It was explained by the need of a very different fatty acid profile to obtain a different melting profile.

Kim et al. (2005b) suggested a tendency present among the different milk fat fractions studied by GC, high-melting triglyceride species (saturated fatty acid C6-C18) seem slightly more concen-

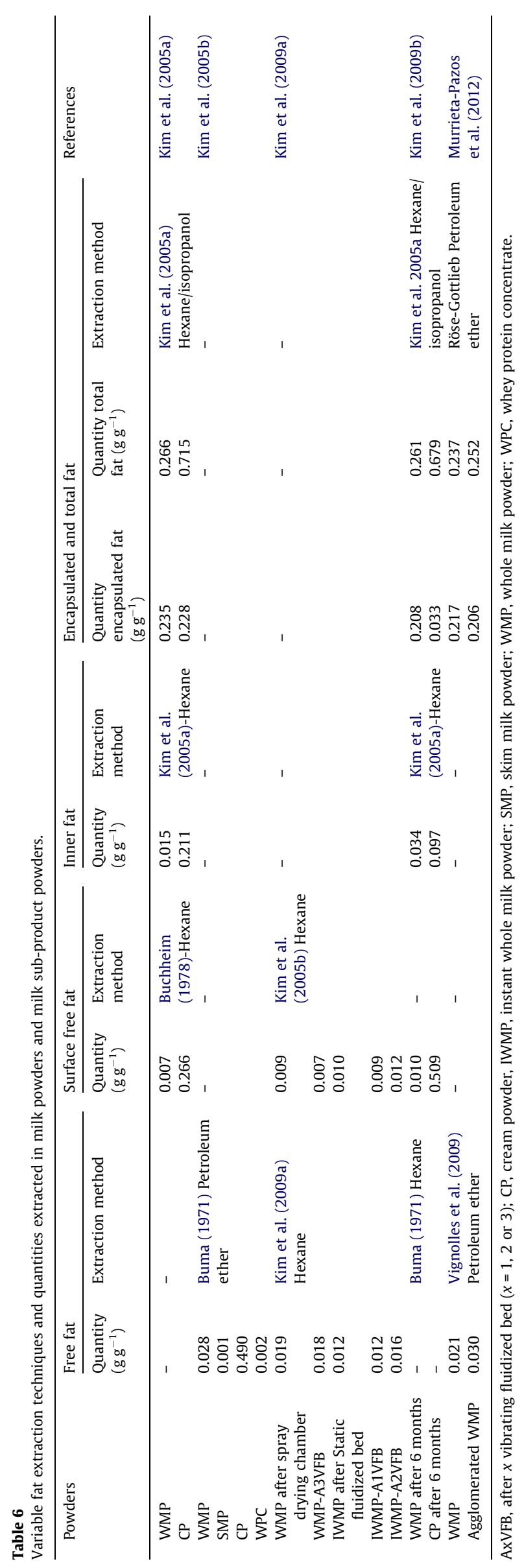


trated in the free-fat fractions and low-melting triglyceride species (unsaturated fatty acid C16-C18) seem more concentrated in the encapsulated fat, this results agree with those obtained by Murrieta-Pazos et al. (2012) for WMP. No significant differences were observed by GC between fat fractions obtained from standard and agglomerated powder, meaning that functional differences observed between these powders were not due to different fat compositions (Murrieta-Pazos et al., 2012).

Changes in the surface composition during long term storage of WMP and CP were studied by gaseous chromatography (GC) and reversed-phase high performance liquid chromatography (HPLC) were studied by Kim et al. (2009b). After 6 months storage was observed in the inner free fat a decrease in the long-chain saturated fatty acids (C16:0 and $C$ 18:0) with concurrent increases in the long-chain unsaturated fatty acids (C16:1 and C18:1-C18:3). This was in agreement with the triglyceride profile obtained by HPLC. The results showed that inner free fat had higher concentration of low-melting triglycerides (C24-34) and medium-melting triglycerides (C36-C40) compared with other milk fat fractions. High-melting triglycerides were found to be slightly more concentrated in the surface free fat. A release of low-melting triglycerides towards the surface of the powder during storage was observed in both WMP and CP.

\section{Inverse gas chromatography (IGC)}

The functionality of food powders can be affected by surface property modifications caused by external factors such as ambient humidity, the surface amorphous content generated by the process, or the storage conditions. It is also of interest to modify the surface functionality by addition of a flavor compound or emulsifier. Inverse gas chromatography (IGC) appears as an efficient tool to investigate surface modifications of food powders under different parameters.

In contrast to conventional gas chromatography where a known stationary phase separates and identifies various components, IGC uses identified molecules called probes, to determine surface properties of a solid packed into a column. IGC can provide different physical chemistry parameters of the solid surface such as surface energy, thermal transitions, crystallinity, specific surface area, and thermodynamic properties of the probe-solid system including heats of adsorption, free energy and entropy of adsorption.

Depending on the amount of injected probes, two techniques of IGC can be distinguished: IGC at infinite dilution consisting of the injection of a very minute amount of probe vapor corresponding to the beginning of the isotherm, or IGC at finite concentration with injection of some microliters of liquid probe in order to cover approximately the surface of the solid with one monolayer. This second technique permits the plotting of sorption isotherms for different organic probes or water molecules. The theory is already well detailed elsewhere (Conder and Young, 1979).

In the food field, IGC was used for several years mainly to study the influence of moisture on surface properties of food products and to determine their interactions with aroma compounds. As shown in the following paragraphs, different food powders were investigated such as wheat or corn starch, wheat gluten, collagen, soy protein, sugars (lactose, glucose, sucrose, raffinose), chitin, pasta products, dry bakery products, theophylline and caffeine.

\subsection{IGC and moisture adsorption isotherms to investigate interactions} between humidity and food components

IGC is a rapid and efficient technique for the determination of moisture adsorption isotherms. Coelho et al. (1979b) showed the presence of water-polymer interactions from water isotherms on collagen. The isosteric heat of adsorption is higher at low moisture content, revealing the adsorption of water molecules on the most active sites. It then drops slightly to a constant value of $6.8 \mathrm{kcal} /$ mol, characteristic of hydrogen bonding.

They also proved the absence of clustering of water molecules in collagen by the calculation of the value of the Zimm-Lundberg cluster function $C_{1} G_{11}$ (Zimm and Lundberg, 1956), the result was negative. It should be highlighted that if this function has a negative value the water molecules are dispersed and adsorbed on active sites on the solid surface. On the contrary, a positive value of this function indicates the presence of clusters of water molecules.

In the cereals field, IGC was used to study water sorption by wheat flour (Riganakos et al., 1989). Two different mechanisms were suggested: at lower water vapor pressures, the water molecules adsorb themselves on the active sites of high binding energies such as $\mathrm{C}=\mathrm{O}, \mathrm{COO}^{-}$or $\mathrm{NH}_{4}^{+}$, and at higher moisture contents $\left(>25 \times 10^{-3} \mathrm{~atm}\right)$, water clusters are formed showing that waterwater interactions are favored. This is shown by the value of the cluster function $C_{1} G_{11}$ upper to 0 (Table 7). Water isotherms were successfully fitted to the BET, GAB and Freundlich isotherm models. Riganakos et al. (1994) compared the gravimetric (the static method with saturated salt slurries) with two IGC methods (called IGC and CIGC respectively corresponding to several injections or a single large solute injection) to obtain water sorption by wheat and

Table 7

Zimm-Lundberg cluster analysis for two systems: water-raffinose and water-wheat flour at $30^{\circ} \mathrm{C}$.

\begin{tabular}{|c|c|c|c|c|c|}
\hline System & $a\left(\mathrm{mg} \mathrm{H}_{2} \mathrm{O} \mathrm{g}^{-1}\right.$ solid $)$ & p. $10^{3}$ (atm) & $a_{\mathrm{w}}\left(p / p_{0}\right)$ & $\mathrm{C}_{1} \mathrm{G}_{11}$ & References \\
\hline \multirow[t]{10}{*}{ Water-wheat flour } & 10 & 0.37 & 0.01 & -0.35 & \multirow[t]{10}{*}{ Riganakos et al. (1989) } \\
\hline & 20 & 1.85 & 0.04 & -0.65 & \\
\hline & 30 & 4.63 & 0.11 & -0.85 & \\
\hline & 40 & 14.80 & 0.35 & -0.60 & \\
\hline & 50 & 23.87 & 0.57 & -0.16 & \\
\hline & 60 & 27.20 & 0.65 & 0.05 & \\
\hline & 70 & 29.97 & 0.72 & 0.29 & \\
\hline & 80 & 32.38 & 0.77 & 0.55 & \\
\hline & 90 & 34.60 & 0.83 & 0.85 & \\
\hline & 100 & 36.63 & 0.87 & 1.14 & \\
\hline \multirow[t]{6}{*}{ Water-raffinose } & 1.0 & 7.2 & 0.17 & -0.25 & \multirow[t]{6}{*}{ Demertzis et al. (1989) } \\
\hline & 2.0 & 17.0 & 0.41 & +0.07 & \\
\hline & 3.0 & 22.8 & 0.52 & +0.54 & \\
\hline & 4.0 & 26.9 & 0.64 & +1.28 & \\
\hline & 4.5 & 27.7 & 0.66 & +1.54 & \\
\hline & 5.0 & 28.7 & 0.69 & +1.86 & \\
\hline
\end{tabular}

$a$, water uptake; $a_{\mathrm{w}}$, water activity; $\mathrm{C}_{1} \mathrm{G}_{11}$, cluster function; $p$, pressure of water. 
Table 8

BET and GAB isotherm constants for water sorption in wheat and soy flours using the static gravimetric, IGC and CIGC sorption methods at $30^{\circ} \mathrm{C}$ (Riganakos et al., 1994).

\begin{tabular}{|c|c|c|c|c|c|c|}
\hline \multirow[t]{2}{*}{ Method } & \multirow[t]{2}{*}{ Powder } & \multicolumn{2}{|c|}{ BET model } & \multicolumn{3}{|c|}{ GAB model } \\
\hline & & $V_{\mathrm{m}}(\mathrm{g} / \mathrm{g})$ & $\mathrm{C}$ & $W_{\mathrm{m}}(\mathrm{g} / \mathrm{g})$ & $\mathrm{C}$ & $\mathrm{K}$ \\
\hline Gravimetric & Wheat flour & 0.068 & 36.90 & 0.065 & 26.48 & 0.94 \\
\hline IGC & & 0.063 & 34.28 & 0.063 & 20.28 & 0.91 \\
\hline CIGC & & 0.061 & 30.48 & 0.062 & 20.84 & 0.91 \\
\hline Gravimetric & Soy flour & 0.050 & 15.28 & 0.048 & 20.48 & 0.90 \\
\hline IGC & & 0.055 & 20.78 & 0.050 & 25.30 & 0.96 \\
\hline CIGC & & 0.051 & 14.04 & 0.053 & 17.20 & 0.94 \\
\hline
\end{tabular}

soy flour. The publication of Coelho et al. (1979a) gives the details about the plot of the moisture sorption isotherm with these two methods. There was an excellent agreement between monolayer values using the three methods (Table 8 ).

The same authors also obtained moisture sorption isotherms on polysaccharides such as apple and citrus pectin (Demertzis et al., 1991) and on crystalline raffinose (Demertzis et al., 1989). The monolayer values for crystalline raffinose calculated with the BET model at different temperatures are much lower $(1.30 \mathrm{mg}$ $\mathrm{H}_{2} \mathrm{O} \mathrm{g}^{-1}$ solid at $35^{\circ} \mathrm{C}$ ) than those reported for other sugars such as lactose (32 $\mathrm{mg} \mathrm{H}_{2} \mathrm{O} \mathrm{g}^{-1}$ solid at $34^{\circ} \mathrm{C}$ ) and sucrose $(99 \mathrm{mg}$ $\mathrm{H}_{2} \mathrm{O} \mathrm{g}^{-1}$ solid at $35{ }^{\circ} \mathrm{C}$ ). This could be attributed to the high degree of crystallinity of raffinose, the higher is the degree of crystallinity, the higher the hydrophobic character of the sugar and the tendency to form clusters. This leads to a lower water monolayer value. The water-water interactions are favored with regard to the hydrophobic surface-water interaction. Results of the ZimmLundberg cluster analysis show that cluster formation is favored on raffinose even at relatively low water pressures (Table 7). The cluster function $C_{1} G_{11}$ is greater than 0 from a pressure equal to $17 \times 10^{-3} \mathrm{~atm}$. If we compare the two powders, wheat flour and raffinose, at any given pressure, the water uptake is much lower for raffinose than for wheat flour. The effect of crystallinity was also reported by Smith et al. (1981) on water sorption isotherms of sucrose (crystalline saccharose) and amorphous glucose. The ability to sorb a given amount of water is greater for the amorphous sugar than for the crystalline one. However the authors overlooked some key aspects during the investigations. The nitrogen specific surface area of the two sugars that can influence water sorption was not taken into account. Also, the BET equation was used to calculate the monolayer coverage with water, however the data did not conform to the linearized BET equation. The authors then interpreted this non-conformity as a result of a complex sorption mechanism occurring in the very low water activity ranges studied. Helen and Gilbert (1985) compared water sorption isotherms of two bakery products: crackers (high in fat and low in sugar) and sweet biscuits. The cracker absorbs significantly more moisture than the sweet biscuit, indicating a higher hygroscopicity of the crackers. The clustering analysis indicated that water-food interactions were favored in the crackers compared with waterwater interactions in sweet biscuits. An experiment consisting of
Table 10

Surface properties of $\alpha$-lactose monohydrate at $30^{\circ} \mathrm{C}$ after conditioning at $40{ }^{\circ} \mathrm{C}$ (Ticehurst et al., 1996).

\begin{tabular}{llllll}
\hline Samples & $\gamma_{S}^{D}\left(\mathrm{~mJ} / \mathrm{m}^{2}\right)$ & \multicolumn{4}{l}{$-\Delta G^{\mathrm{sp}}(\mathrm{kJ} / \mathrm{mol})$} \\
\cline { 3 - 6 } & & Acetone & THF & Ether & Ethyl acetate \\
\hline Batch A & $44 \pm 2$ & $9.1 \pm 0.3$ & $7.3 \pm 0.2$ & $6.0 \pm 0.2$ & $8.6 \pm 0.2$ \\
Batch B & 40 & 5.7 & 4.4 & 2.9 & 5.4 \\
Batch C & $41 \pm 3$ & $8.2 \pm 0.3$ & $6.6 \pm 0.2$ & $5.2 \pm 0.2$ & $7.8 \pm 0.2$ \\
Batch D & 42 & 8.7 & 6.9 & 5.4 & 7.7 \\
\hline
\end{tabular}

adding increasing amounts of crystalline sucrose to crackers leads to a decrease of their hygroscopicity. This favours the formation of water clustering and shows the isotherm of crackers tend to that of the sweet biscuit. This study also confirms that higher is the crystalline character of a powder, smaller is the capacity to absorb water and the formation of water clustering is favored. Pasta products were analyzed by Lagoudaki et al. (1993), who compared moisture sorption isotherms of conventional and diet spaghetti. The capacity to sorb water is higher for conventional spaghetti than for diet spaghetti, due to its higher carbohydrate content. The same authors (Lagoudaki and Demertzis, 1994) also compared the effects of moisture and temperature on the water sorption of dehydrated food constituents such as potato starch, egg albumin and wheat gluten. Table 9 gathers the BET and GAP isotherm constants for water sorption at $30^{\circ} \mathrm{C}$ on potato starch, egg albumin, wheat gluten and spaghetti.

\subsection{IGC a technique used to study surface amorphous content}

Performance of a solid in different processes can be related to its amorphous content especially located at the surface. So techniques like IGC which are able to quantify amorphous content on a solid surface are of great interest. Different works were carried out on lactose using IGC. Ticehurst et al. (1996) examined four batches of lactose (Batches A, B, C and D), which exhibited variable processing performance but were revealed identical by usual physical and chemical techniques. Only IGC led to different surface properties. Table 10 gathers values of the dispersive component of the surface energy, $\gamma_{s}^{D}$ and specific free energy of adsorption, $\Delta G^{\mathrm{sp}}$ of different polar probes for the four batches. If the $\gamma_{s}^{D}$ are comparable, the $\Delta G^{\text {sp }}$ for polar probes exhibit significant differences, indicating variations in the polar surface properties between the batches.

The lactose was also studied to show some relationships between IGC parameters and amorphous content on the solid surface (Newell et al., 2001a; Newell and Buckton, 2004). Three samples of lactose were compared by IGC: a crystalline lactose, a spray dried $100 \%$ amorphous lactose and a milled lactose with less than $1 \%$ amorphous content by mass. The milled lactose was noted to have a similar dispersive surface energy $\left(41.6 \mathrm{~mJ} / \mathrm{m}^{2}\right)$ to the $100 \%$ amorphous lactose $\left(37.1 \mathrm{~mJ} / \mathrm{m}^{2}\right)$, indicating that the amorphous was preferentially located on the surface. This result revealed that milling disrupts the surface more than the bulk. For comparison, the dispersive surface energy value for the crystalline lactose was

Table 9

BET and GAB isotherm constants for water sorption in spaghetti, potato starch, egg albumin and wheat gluten at $30^{\circ} \mathrm{C}$.

\begin{tabular}{|c|c|c|c|c|c|c|}
\hline \multirow[t]{2}{*}{ Sample } & \multicolumn{2}{|l|}{ BET model } & \multicolumn{3}{|l|}{ GAB model } & \multirow[t]{2}{*}{ References } \\
\hline & $V_{\mathrm{m}}(\mathrm{g} / \mathrm{g})$ & C & $W_{\mathrm{m}}(\mathrm{g} / \mathrm{g})$ & $\mathrm{K}$ & C & \\
\hline Conventional spaghetti & $0.0604 \pm 0.0018$ & $7.77 \pm 4.2$ & $0.0770 \pm 0.0112$ & $0.84 \pm 0.08$ & $7.48 \pm 1.22$ & Lagoudaki et al. (1993) \\
\hline Diet spaghetti & $0.0548 \pm 0.0060$ & $7.13 \pm 2.5$ & $0.0589 \pm 0.0155$ & $0.84 \pm 0.30$ & $6.54 \pm 1.37$ & \\
\hline Potato starch & $0.0675 \pm 0.0055$ & $14.04 \pm 1.66$ & $0.0906 \pm 0.0083$ & $0.73 \pm 0.08$ & $10.48 \pm 1.72$ & Lagoudaki and Demertzis, 1994 \\
\hline Egg albumin & $0.0537 \pm 0.0058$ & $7.91 \pm 1.73$ & $0.0576 \pm 0.0073$ & $0.77 \pm 0.08$ & $7.17 \pm 1.33$ & \\
\hline Wheat gluten & $0.0440 \pm 0.0048$ & $7.49 \pm 1.15$ & $0.0530 \pm 0.0055$ & $0.85 \pm 0.01$ & $7.32 \pm 1.57$ & \\
\hline
\end{tabular}


Table 11

Heats of adsorption on two solids: soy protein isolate and lactose obtained by different authors.

\begin{tabular}{|c|c|c|c|c|}
\hline \multirow[t]{3}{*}{ Flavor } & \multicolumn{4}{|l|}{$-\Delta H(\mathrm{kcal} / \mathrm{mol})$} \\
\hline & \multicolumn{3}{|l|}{ Soy protein isolate } & \multirow{2}{*}{$\begin{array}{l}\text { Lactose } \\
\text { McMullin et al. (1975) }\end{array}$} \\
\hline & Aspelund and Wilson (1983) & Crowther et al. (1981) & Zhou and Cadwallader $(2006,2004)$ & \\
\hline$n$-Hexane & - & - & 6.8 & - \\
\hline n-Nonane & 6.52 & - & - & 9.24 \\
\hline$n$-Decane & 8.36 & - & - & 10.55 \\
\hline Hexanal & 8.89 & 11.1 & 10.3 & 11.63 \\
\hline Methyl $n$-butyrate & & - & - & 10.65 \\
\hline Methyl $n$-pentanoate & 6.71 & - & - & 12.14 \\
\hline Methyl $n$-hexanoate & 8.19 & - & - & 13.57 \\
\hline 2-Pentanone & 2.92 & 10.1 & - & 10.81 \\
\hline 2-Hexanone & 6.04 & 11.0 & 10.5 & 12.03 \\
\hline 2-Heptanone & 8.11 & 12.7 & - & 13.09 \\
\hline 1-Pentanol & 11.25 & 13.1 & - & 16.03 \\
\hline 1-Hexanol & 13.89 & 16.7 & 16.3 & 17.57 \\
\hline 1-Heptanol & 18.06 & 16.8 & - & 17.18 \\
\hline
\end{tabular}

equal to $31.2 \mathrm{~mJ} / \mathrm{m}^{2}$. The same authors (Newell et al., 2001b) also showed that under humid conditions $(0-20 \% \mathrm{RH})$, the dispersive component of the surface energy of amorphous lactose was reduced to the value of the crystalline one, giving evidence of crystallization.

Ambarkhane et al. (2005) compared IGC and gravimetric vapor sorption to study the behavior of amorphous lactose during the water sorption. The data made it possible to determinate: (1) a first transition at low RH (ca. 10\% RH) corresponding to the onset of significant molecular mobility in the amorphous material; (2) the glass transition followed by the collapse of amorphous lactose occurring between $30 \%$ and $40 \% \mathrm{RH}$; and (3) the onset of crystallization above $45 \% \mathrm{RH}$. The authors showed that at each temperature $\mathrm{T}$ of analysis, the amorphous lactose crystallizes when $\operatorname{Tg}_{\text {mix }}$ (using the Gordon-Taylor equation taking into account the masses and $\mathrm{Tg}$ of water and dry amorphous lactose) is $32{ }^{\circ} \mathrm{C}$ below $\mathrm{T}$.

Recently the first paper where quantification of surface amorphous content was realised thanks to the measurement of the dispersive surface component, was published (Brum and Burnett, 2011). The authors wrote, for a solid composed of two kinds of surfaces (e.g. a physical mixture of crystalline and amorphous solids) the effective surface energy of the mixture, $\gamma_{\text {Seff }}^{D}$ (the net effect of the heterogeneous surface on the probe) is related to the linear combination of the square roots of the surface area normalized dispersive energy terms of each solid $\gamma_{S 1}^{D}$ et $\gamma_{S 2}^{D}$ :

$\left(\gamma_{\text {Seff }}^{D}\right)^{1 / 2}=\phi_{1}\left(\gamma_{S 1}^{D}\right)^{1 / 2}+\phi_{2}\left(\gamma_{S 2}^{D}\right)^{1 / 2}$

where $\phi_{x}$ are the respective surface fractions of each solid.

The values $\gamma_{S 1}^{D}$ and $\gamma_{S 2}^{D}$ are determined by the pure solids reference. This calculation needs crystalline and amorphous references. The authors warned against the reference material; if the amorphous contains other surface disorders (i.e. fractures, defect sites, etc.) its energies will be interpreted against amorphous references. The first test reviewed on lactose. Crystalline $\alpha$-lactose monohydrate and spray-dried lactose were respectively taken as the crystalline and the fully amorphous surface references. From these reference materials, several physical mixtures were prepared in order to measure the difference in $\gamma_{s}^{D}$ and to compare them with the theoretical values. There is excellent agreement between experimental data and the theoretical prediction based on the surface energies of the crystalline and amorphous references. IGC gives only the surface amorphous content. A bulk technique, DSC, was carried out to evaluate the bulk amorphous content. Comparing the IGC and DSC amorphous content showed how disorder was distributed throughout the particle. For the micronized sample, the disorder resides only at the solid surface. The partially recrystallized spray-dried sample presents an energetic surface as well as bulk corresponding to a significant amorphous percentage ( $\sim 70 \%$ ). The ball milled particles lead to very high surface amorphous content while the bulk gives around 5\%.

To conclude, IGC appears as an efficient tool to evaluate the surface amorphous content and the amorphous phase, which can be desirable (e.g. to stabilize proteins) or undesirable (e.g. can decrease the stability and induce changes in product performance).

\subsection{IGC to investigate interactions between flavor compounds and food components}

IGC is also of interest in the food field regarding the study of interactions between flavor compounds and food components. These compounds have a great impact on the flavor of the final food product. IGC is a powerful tool to investigate the adsorption of flavor compounds onto solid support such as proteins, starch and sugars.

One of the first studies on this subject was realized by McMullin et al. (1975), which demonstrated that lactose has a great ability to adsorb aromas. The heats of adsorption of a large variety of organic compounds (esters, aldehydes, ketones, alcohols and hydrocarbons) on anhydrous lactose were compared (Table 11). For a given number of carbon atoms alcohols have the highest heats of adsorption, hydrocarbons have the lowest, and the other functions adsorb with intermediate strengths. The hydrogen bonds formed between the lactose and the functional groups of organic compounds, such as hydroxyl for alcohols, was supposed to be the major factor involved in the strength of adsorption.

Soy protein is also of much interest in the food field. Different authors also studied interactions between soy protein and aroma compounds. Crowther et al. (1981) compared adsorption coefficients and heats of adsorption of a number of volatile organics onto soy protein isolate (SPI) after treatments involving different levels of temperature, moisture and shear. They observed changes in adsorption coefficients of the treated samples attributed to a decrease in binding due to the protein denaturation. Aspelund and Wilson (1983) also measured heats of adsorption to determine strengths of adsorption of flavors onto SPI (Table 11). They noticed that the hydrocarbons adsorbed the weakest and the alcohols the strongest onto dry soy protein. The former interact only with non-specific interactions (Van der Waals), the latter interact not only with nonspecific interactions but also with specific ones and especially hydrogen bonds. Zhou and Cadwallader (2004) also arrived at the same conclusion as Aspelund and Wilson (1983). 
Table 12

Effect of adsorbed lecithin and PGPR at the sucrose surface (Rousset et al., 2002).

\begin{tabular}{lllllll}
\hline & \multicolumn{2}{l}{ Granulated sucrose } & & & \multicolumn{2}{l}{ Jet milled sucrose } \\
\cline { 2 - 3 } & Without emulsifiers & With lecithin & With PGPR & & Without emulsifiers & With lecithin \\
\hline$\gamma_{S}^{D}\left(\mathrm{~mJ} / \mathrm{m}^{2}\right)$ & 30.3 & 30.6 & 31.1 & 36.5 & 30.9 \\
$K_{\mathrm{A}} \times 10^{-2}$ & 18 & 15 & 15 & 19 & 30.0 \\
$K_{\mathrm{B}} \times 10^{-2}$ & 23 & 28 & 33 & 22 & 26 \\
\hline
\end{tabular}

Volatile polar probes such as 1-hexanol and hexanal have higher binding affinities than an apolar one (hexane) due to hydrogen binding interactions with SPI. The retention of these polar probes are weaker at $30 \% \mathrm{RH}$, indicating possible competition for binding sites on the SPI surface between these volatile probes and water molecules. The same authors (Zhou and Cadwallader, 2006) completed their first study on SPI by investigating the influence of flavor compound chemical structure, including functional groups (hydrocarbons, esters, ketones, aldehydes and alcohols) and stereochemistry (position of a double bond, or the distance between a double bond and an hydroxyl group) on binding. They compared thermodynamic and sorption data under different relative humidities.

Boutboul et al. (2000) investigated the interactions between aromas and native corn starch. They observed that retention was higher under humid conditions than under dry conditions especially for alcohols. The authors proposed different hypotheses; on one hand a predominant adsorption phenomenon involving hydrogen bonds between aroma compounds such as alcohols, and glucose residues of the starch. On the other hand, a solvation of aroma compounds by water molecules allows for their diffusion through the starch matrix. Boutboul et al. (2002) also obtained different sorption isotherms on starch depending on the aroma compounds and the interactions developed between the starch and the aroma compounds (type II for an ester, type III for d-limonene and linear for an aldehyde and an alcohol).

\subsection{IGC to assess the modifications of surfaces after coating by emulsifiers}

IGC is also a useful tool for the assessment of the modifications of surface properties of powders after different treatments. The evolution of surface properties of sucrose coated by emulsifiers commonly used in chocolate, lecithin or polyglycerol polyricinoleate (PGPR), was monitored by IGC (Rousset et al. 2002) (Table 12). The adsorption of the emulsifiers decreases the acidic character (Ka parameter) originating from the hydroxyl group and consequently increases the lipophilicity of the sucrose. The sucrose-sucrose interactions are weaker inducing an increase in the fluidity of fat-based suspensions like chocolate.

\section{Conclusion and perspectives}

For a better understanding of the relationships between surface properties and functional properties it is absolutely necessary to characterize the powder surface in detail. For this purpose, specific analytical methods (physico-chemistry and surface physics) able to evaluate the surface properties of the food powders are needed. Some techniques are now well developed in the food powder fields (XPS, SEM). However others may need more attention from the scientific community (TOF-SIMS, particle morphology, EDX). In Fig. 3, an example of multiscale surface investigation is presented. Coupling atomic, molecular, microstructural and physical approaches

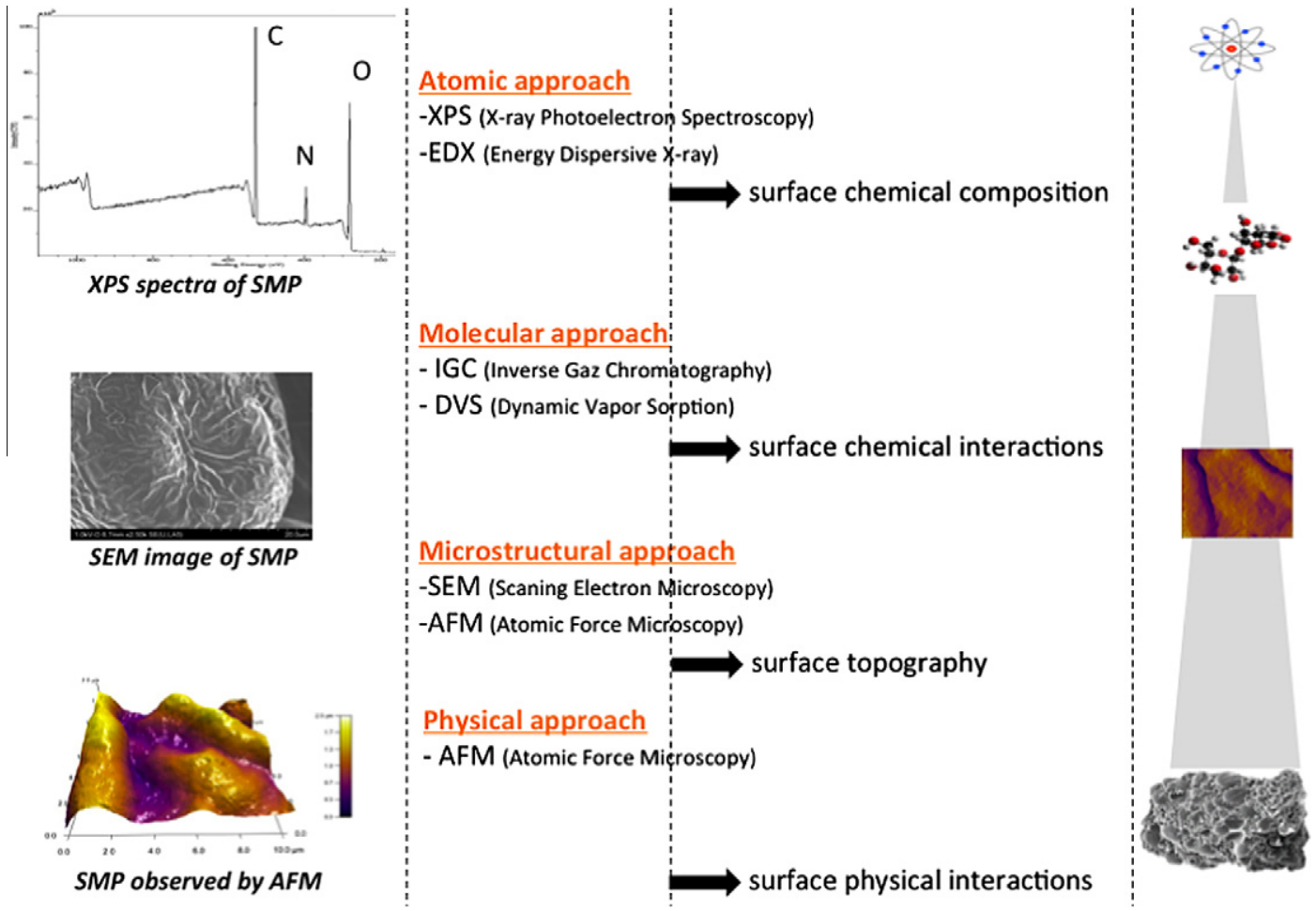

Fig. 3. Techniques for surface characterization at different levels regarding information content and scale. 


\section{FOOD PARTICLE}

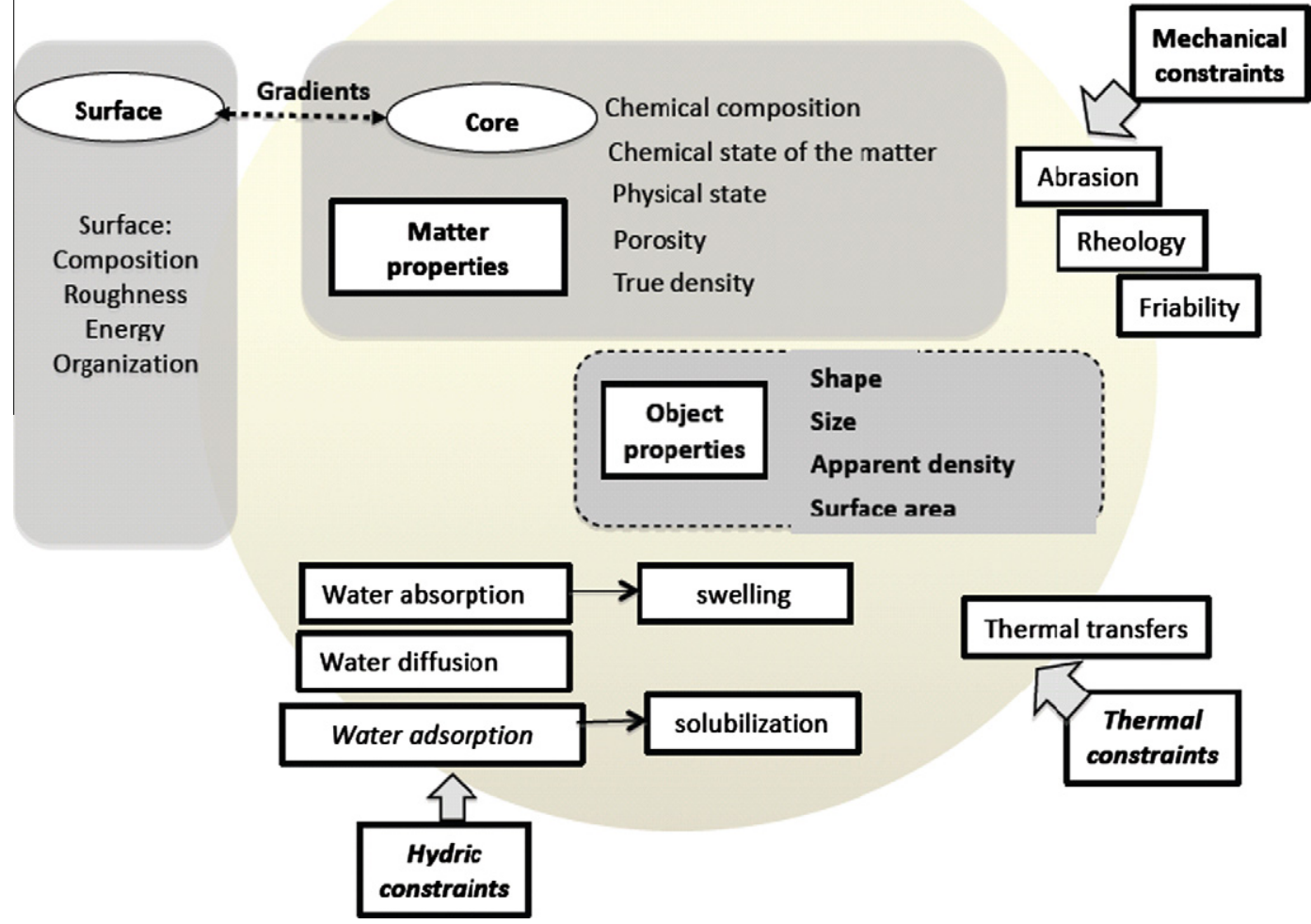

Fig. 4. Links between surface characterization, physico-chemical process and constraints (hydric, thermal and mechanical).

may be an interesting option to best understand the surface reactivity. Concurrently, some techniques, like IGC, were rarely used on food powders and may be an efficient tool to evaluate the modifications of surface properties of a powder under wet conditions, or the adsorption of flavor compounds which has a great impact on the flavor of the final product. Recently, IGC was also carried out to quantify the surface amorphous content and the amorphous phase (desirable or undesirable) for the stability of the powder.

Concurrently, research is needed to bind basic approaches with technological applications, while integrating the contribution of both particle surface and process parameters occurring from powder manufacturing to end-products. The principal functional properties of a food powder may be linked to water, thermal and/or mechanical constraints. Fig. 4 highlights some links between surface characterization and constraints (hydric, thermal and mechanical).

In conclusion, the surface properties determinations could be of great importance as the surface governs some essential functional properties: wetting, dispersibility, stickiness, flowability, etc. In spite of the only recent use of some techniques, all those presented have been successfully used in the study of food powders.

\section{Acknowledgments}

ANR funding from the "Reactive Powder" program is gratefully thanked. In addition, the first author acknowledges the Research National Association in France, the Mexican National Council of Science and technology and the Complementary Scholarships of SEP in Mexico for financial resources. Carl Sitch is also thanked for English re-reading.

\section{References}

Adhikari, B., Howes, T., Bhandari, B.R., Truong, V., 2001. Stickiness in foods: a review of mechanisms and test methods. International Journal of Food Properties 4 (1), $1-33$.
Al Mahdi, R., Nasirpour, A., Banon, S., Scher, J., Desobry, S., 2006. Morphological and mechanical properties of dried skimmed milk and wheat flour mixtures during storage. Powder Technology 163 (3), 145-151.

Ambarkhane, A.V., Pincott, K., Buckton, G., 2005. The use of inverse gas chromatography and gravimetric vapour sorption to study transitions in amorphous lactose. International Journal of Pharmaceutics 294 (1-2), 129-135.

An, $\mathrm{H}$. Yang, $\mathrm{H}$, Liu, $\mathrm{Z}$, Zhang, $\mathrm{Z}$, 2008. Effects of heating modes and sources on nanostructure of gelatinized starch molecules using atomic force microscopy. LWT - Food Science and Technology 41 (8), 1466-1471.

Aspelund, T.G., Wilson, L.A., 1983. Adsorption of off-flavor compounds onto soy protein: a thermodynamic study. Journal of Agricultural and Food Chemistry 31 (3), 539-545.

Baldwin, P., 1995. Studies on the surface chemistry, minor component composition and structure of granular starches. Ph.D. Thesis, University of Nottingham, UK.

Baldwin, P.M., Davies, M.C., Melia, C.D., 1997. Starch granule surface imaging using low-voltage scanning electron microscopy and atomic force microscopy. International Journal of Biological Macromolecules 21 (1-2), 103-107.

Baldwin, P.M., Adler, J., Davies, M.C., Melia, C.D., 1998. High resolution imaging of starch granule surfaces by atomic force microscopy. Journal of Cereal Science 27 (3), 255-265.

Baldwin, P.M., 2001. Starch granule-associated proteins and polypeptides: a review. Starch - Stärke 53 (10), 475-503.

Barbosa-Canovas, G.V., Lopez, J.M., Peleg, M., 1987. Density and compressibility of selected food powders mixtures. Journal of Food Process Engineering 10 (1), 119.

Bosquillon, C., Rouxhet, P.G., Ahimou, F., Simon, D., Culot, C., Préat, V., Vanbever, R., 2004. Aerosolization properties, surface composition and physical state of spray-dried protein powders. Journal of Controlled Release 99 (3), 357-367.

Boutboul, A., Giampaoli, P., Feigenbaum, A., Ducruet, V., 2000. Use of inverse gas chromatography with humidity control of the carrier gas to characterise aroma-starch interactions. Food Chemistry 71 (3), 387-392.

Boutboul, A., Lenfant, F., Giampaoli, P., Feigenbaum, A., Ducruet, V., 2002. Use of inverse gas chromatography to determine thermodynamic parameters of aroma-starch interactions. Journal of Chromatography A 969 (1-2), 9-16.

Briggs, D. (1994). Practical surface analysis: Auger and X-ray photoelectron spectroscopy, v. 1, second ed., Wiley-Blackwell.

Brum, J., Burnett, D., 2011. Quantification of surface amorphous content using dispersive surface energy: the concept of effective amorphous surface area. AAPS PharmSciTech 12 (3), 887-892.

Buchheim, W., 1978. Distribution of Extractable Fat in Particles Spray Dried Whole Milk. XX International Dairy Congress.

Buma, T.J., 1971. Free fat in spray-dried whole milk X. A final report with a physical model for free-fat in spray-dried milk. Netherlands Milk and Dairy Journal 25, 159-174. 
Chanvrier, H., Colonna, P., Della Valle, G., Lourdin, D., 2005. Structure and mechanical behaviour of corn flour and starch-zein based materials in the glassy state. Carbohydrate Polymers 59 (1), 109-119.

Chau, T.T., Bruckard, W.J., Koh, P.T.L., Nguyen, A.V., 2009. A review of factors that affect contact angle and implications for flotation practice. Advances in Colloid and Interface Science 150 (2), 106-115.

Cliff, B., Lockyer, N., Jungnickel, H., Stephens, G., Vickerman, J.C., 2003. Probing cell chemistry with time-of-flight secondary ion mass spectrometry: development and exploitation of instrumentation for studies of frozen-hydrated biological material. Rapid Communications in Mass Spectrometry: RCM 17 (19), 2163 2167.

Coelho, U., Miltz, J., Gilbert, S.G., 1979a. Application of inverse phase gas chromatography for determination of bound water phase gas chromatography for determination of bound water in collagen. Journal of Food Science 44 (4), 1150-1151.

Coelho, U., Miltz, J., Gilbert, S.G., 1979b. Water binding on collagen by inverse phase gas chromatography: thermodynamic considerations. Macromolecules 12 (2) 284-287.

Conder, J.R., Young, C.L. (Eds.), 1979. Physicochemical Measurement by Gas Chromatography, John Wiley \& Sons Ltd., Chichester, New York.

Crowther, A., Wilson, L.A., Glatz, C.E., 1981. Effect of processing on adsorption of offflavors ont soy protein. Journal of Food Process Engineering 4 (2), 99-115.

Cuq, B., Rondet, E., Abecassis, J., 2011. Food powders engineering, between knowhow and science: constraints, stakes and opportunities. Powder Technology 208 (2), 244-251.

Demertzis, P.G., Riganakos, K.A., Giannakakos, P.N., Kontominas, M.G., 1991. Study of water sorption behaviour of pectins using a computerised elution gas chromatographic technique. Journal of the Science of Food and Agriculture 54 (3), 421-428

Demertzis, P.G., Riganakos, K.A., Kontominas, M.G., 1989. Water sorption isotherms of crystalline raffinose by inverse gas chromatography. International Journal of Food Science and Technology 24 (6), 629-636.

Du, C.-J., Sun, D.-W., 2004. Recent developments in the applications of image processing techniques for food quality evaluation. Trends in Food Science and Technology 15 (5), 230-249.

Fäldt, P., 1995. Surface composition of spray dried emulsions. Ph.D. Thesis. Department of Food Engineering, Lund University, Lund, Sweden.

Fannon, J.E., Shull, J.M., Bemiller, J.N., 1993. Interior channels of starch granules. Cereal Chemistry 70 (5), 611-613.

Farkas, J., Mohácsi-Farkas, C., 1996. Application of differential scanning calorimetry in food research and food quality assurance. Journal of Thermal Analysis 47 (6), 1787-1803.

Focardi, S., Ristori, S., Mazzuoli, S., Tognazzi, A., Leach-Scampavia, D., Castner, D.G. Rossi, C., 2006. ToF-SIMS and PCA studies of Seggianese olives and olive oil. Colloids and Surfaces A: Physicochemical and Engineering Aspects 279 (1-3) 225-232.

Forny, L., Marabi, A., Palzer, S., 2011. Wetting, disintegration and dissolution of agglomerated water soluble powders. Powder Technology 206 (1-2), 72-78.

Freudig, B., Hogekamp, S., Schubert, H., 1999. Dispersion of powders in liquids in a stirred vessel. Chemical Engineering and Processing 38 (4-6), 525-532.

Funami, T., 2010. Atomic force microscopy imaging of food polysaccharides. Food Science and Technology Research 16 (1), 1-12.

Funami, T., Noda, S., Nakauma, N.M., Ishihara, S., Takahashi, R., Al-Assaf, S., Ikeda, S. Nishinari, K., Phillips, G.O., 2008. Molecular structures of gellan gum imaged with atomic force microscopy in relation to the rheological behavior in aqueous systems in the presence or absence of various cations. Journal of Agricultural and Food Chemistry 56 (18), 8609-8618.

Fyfe, K.N., Kravchuk, O., Le, T., Deeth, H.C., Nguyen, A.V., Bhandari, B., 2011. Storage induced changes to high protein powders: influence on surface properties and solubility. Journal of the Science of Food and Agriculture 91 (14), 2566-2575

Gaiani, C., 2006. Etude des mécanismes de réhydratation des poudres laitières: influence de la structure et de la composition des poudres. Ph.D. Thesis, University of Lorraine. Vandoeuvre lès Nancy, France.

Gaiani, C., Banon, S., Scher, J., Schuck, P., Hardy, J., 2005. Use of a turbidity sensor to characterize micellar casein powder rehydration: influence of some technological effects. Journal of Dairy Science 88 (8), 2700-2706.

Gaiani, C., Boyanova, P., Hussain, R., Murrieta Pazos, I., Karam, M.C., Burgain, J. Scher, J., 2011b. Morphological descriptors and colour as a tool to better understand rehydration properties of dairy powders. International Dairy Journal 21 (7), 462-469.

Gaiani, C., Ehrhardt, J.J., Scher, J., Hardy, J., Desobry, S., Banon, S., 2006. Surface composition of dairy powders observed by X-ray photoelectron spectroscopy and effects on their rehydration properties. Colloids and Surfaces B: Biointerfaces 49 (1), 71-78.

Gaiani, C., Morand, M., Sanchez, C., Tehrany, E.A., Jacquot, M., Schuck, P., Jeantet, R. Scher, J., 2010. How surface composition of high milk proteins powders is influenced by spray-drying temperature. Colloids and Surfaces B: Biointerfaces 75 (1), 377-384.

Gaiani, C., Mullet, M., Arab Tehrany, E., Jacquot, M., Perroud, C., Renard, A., Scher, J., 2011a. Milk proteins differentiation and competitive adsorption during spraydrying. Food Hydrocolloids 25 (5), 983-990.

Gaiani, C., Scher, J., Ehrhardt, J.J., Linder, M., Schuck, P., Desobry, S., Banon, S., 2007. Relationships between dairy powder surface composition and wetting properties during storage: importance of residual lipids. Journal of Agricultural and Food Chemistry 55 (16), 6561-6567.
Gaiani, C., Schuck, P., Scher, J., Ehrhardt, J.J., Arab-Tehrany, E., Jacquot, V., Banon, S. 2009. Native phosphocaseinate powder during storage: lipids released onto the surface. Journal of Food Engineering 94 (2), 130-134.

Gallant, D.J., Bouchet, B., Baldwin, P.M., 1997. Microscopy of starch: evidence of a new level of granule organization. Carbohydrate Polymers 32 (3-4), 177-191.

Grenha, A., Seijo, B., Serra, C., Remuñan-López, C., 2007. Chitosan nanoparticleloaded mannitol microspheres: structure and surface characterization. Biomacromolecules 8 (7), 2072-2079.

Gunning, A.P., Kirby, A.R., Parker, M.L., Cross, K.L., Morris, J., 2010. Utilizing atomic force microscopy in food research. Food Technology 64 (12), 32-37.

Haque, M.K., Roos, Y.H., 2006. Differences in the physical state and thermal behavior of spray-dried and freeze-dried lactose and lactose/protein mixtures. Innovative Food Science and Emerging Technologies 7 (1-2), 62-73.

Hartmann, M., Palzer, S., 2011. Caking of amorphous powders - material aspects, modelling and applications. Powder Technology 206 (1-2), 112-121.

Helen, H.J., Gilbert, S.G., 1985. Moisture sorption of dry bakery products by inverse gas chromatography. Journal of Food Science 50 (2), 454-458.

Hentschel, M.L., Page, N.W., 2003. Selection of descriptors for particle shape characterization. Particle and Particle Systems Characterization 20 (1), 25-38.

Iijima, M., Shinozaki, M., Hatakeyama, T., Takahashi, M., Hatakeyama, H., 2007. AFM studies on gelation mechanism of xanthan gum hydrogels. Carbohydrate Polymers 68 (4), 701-707.

James, B.J., Smith, B.G., 2009. Surface structure and composition of fresh and bloomed chocolate analysed using X-ray photoelectron spectroscopy, cryoscanning electron microscopy and environmental scanning electron microscopy. LWT - Food Science and Technology 42 (5), 929-937.

Jayasundera, M., Adhikari, B.P., Adhikari, R., Aldred, P., 2010. The effect of food-grade low-molecular-weight surfactants and sodium caseinate on spray drying of sugar-rich foods. Food Biophysics 5 (2), 128-137.

Jayasundera, M., Adhikari, B., Adhikari, R., Aldred, P., 2011a. The effect of protein types and low molecular weight surfactants on spray drying of sugar-rich foods. Food Hydrocolloids 25 (3), 459-469.

Jayasundera, M., Adhikari, B., Adhikari, R., Aldred, P., 2011b. The effects of proteins and low molecular weight surfactants on spray drying of model sugar-rich foods: powder production and characterisation. Journal of Food Engineering 104 (2), 259-271.

Jayasundera, M., Adhikari, B., Aldred, P., Ghandi, A., 2009. Surface modification of spray dried food and emulsion powders with surface-active proteins: a review. Journal of Food Engineering 93 (3), 266-277.

Jayasundera, M., Adhikari, B., Howes, T., Aldred, P., 2011c. Surface protein coverage and its implications on spray-drying of model sugar-rich foods: solubility, powder production and characterisation. Food Chemistry 128 (4), 1003-1016.

Jenni, K., 2007. Caractérisation des propriétés de surface de poudres alimentaires: farine de blé. Master report. Université de Montpellier, France.

Kim, E.H.J., 2008. Surface composition of industrial spray-dried dairy powders and its formation mechanisms. Ph.D. Thesis, University of Auckland. Auckland, New Zealand.

Kim, E.H.J., Chen, X.D., Pearce, D., 2002. Surface characterization of four industrial spray-dried dairy powders in relation to chemical composition, structure and wetting property. Colloids and Surfaces B: Biointerfaces 26 (3), 197-212.

Kim, E.H.J., Chen, X.D., Pearce, D., 2005a. Melting characteristics of fat present on the surface of industrial spray-dried dairy powders. Colloids and Surfaces B: Biointerfaces 42 (1), 1-8.

Kim, E.H.J., Chen, X.D., Pearce, D., 2005b. Effect of surface composition on the flowability of industrial spray-dried dairy powders. Colloids and Surfaces B: Biointerfaces 46 (3), 182-187.

Kim, E.H.J., Chen, X.D., Pearce, D., 2009a. Surface composition of industrial spraydried milk powders. 1. Development of surface composition during manufacture. Journal of Food Engineering 94 (2), 163-168.

Kim, E.H.J., Chen, X.D., Pearce, D., 2009b. Surface composition of industrial spraydried milk powders. 3. Changes in the surface composition during long-term storage. Journal of Food Engineering 94 (2), 182-191.

Kim, E.H.J., Chen, X.D., Pearce, D., 2009c. Surface composition of industrial spraydried milk powders. 2. Effects of spray drying conditions on the surface composition. Journal of Food Engineering 94 (2), 169-181.

Kirby, A.R., MacDougall, A.J., Morris, V.J., 2008. Atomic force microscopy of tomato and sugar beet pectin molecules. Carbohydrate Polymers 71 (4), 640-647.

Knowlton, T.M., Carson, J.W., Klinzing, J.W., Yang, W.C., 1994. The importance of storage, transfer and collection. Chemical Engineering Progress 90 (4), 44-54.

Lagoudaki, M., Demertzis, P.G., 1994. Equilibrium moisture characteristics of dehydrated food constituents as studied by a modified inverse gas chromatographic method. Journal of the Science of Food and Agriculture 65 (1), 101-109.

Lagoudaki, M., Demertzis, P.G., Kontominas, M.G., 1993. Moisture Adsorption Behaviour of Pasta Products. Lebensmittel-Wissenschaft und-Technologie 26 (6), 512-516.

Lukasiewicz, M. Ptaszek, A., Koziel, L., Achremowicz, B., Grzesik, M. 2007. Carboxymethylcellulose/polyaniline blends. Synthesis and properties. Polymer Bulletin 58 (1), 281-288.

Marabi, A., Raemy, A., Bauwens, I., Burbidge, A., Wallach, R., Saguy, I.S., 2008. Effect of fat content on the dissolution enthalpy and kinetics of a model food powder. Journal of Food Engineering 85 (4), 518-527.

Mathlouthi, M., Rogé, B., 2003. Water vapour sorption isotherms and the caking of food powders. Food Chemistry 82 (1), 61-71.

McKenna, A.B., 1997. Examination of whole milk powder by confocal laser scanning microscopy. Journal of Dairy Research 64 (3), 423-432. 
McKenna, A.B., Lloyd, R.J., Munro, P.A., Singh, H., 1999. Microstructure of whole milk powder and of insolubles detected by powder functional testing. Scanning 21 (5), 305-315.

McMullin, S.L., Bernhard, R.A., Nickerson, T.A., 1975. Heats of adsorption of small molecules on lactose. Journal of Agricultural and Food Chemistry 23 (3), 452458.

Millqvist-Fureby, A., Elofsson, U., Bergenståhl, B., 2001. Surface composition of spray-dried milk protein-stabilised emulsions in relation to pre-heat treatment of proteins. Colloids and Surfaces B: Biointerfaces 21 (1-3), 47-58.

Millqvist-Fureby, A., Smith, P., 2007. In situ lecithination of dairy powders in spray-drying for confectionery applications. Food Hydrocolloids 21 (5-6), 920-927.

Murrieta-Pazos, I., Gaiani, C., Galet, L., Cuq, B., Desobry, S., Scher, J., 2011. Comparative study of particle structure evolution during water sorption: skim and whole milk powders. Colloids and Surfaces B: Biointerface 87 (1), 1-10.

Murrieta-Pazos, I., Gaiani, C., Galet, L., Scher, J., 2012. Composition gradient from surface to core in dairy powders: agglomeration effect. Food Hydrocolloids 26 (1), 149-158

Newell, H.E., Buckton, G., Butler, D.A., Thielmann, F., Williams, D.R., 2001a. The use of inverse phase gas chromatography to measure the surface energy of crystalline, amorphous, and recently milled lactose. Pharmaceutical Research 18 (5), 662-666.

Newell, H.E., Buckton, G., Butler, D.A., Thielmann, F., Williams, D.R., 2001b. The use of inverse phase gas chromatography to study the change of surface energy of amorphous lactose as a function of relative humidity and the processes of collapse and crystallisation. International Journal of Pharmaceutics 217 (1-2), 45-56.

Newell, H.E., Buckton, G., 2004. Inverse gas chromatography: investigating whether the technique preferentially probes high energy sites for mixtures of crystalline and amorphous lactose. Pharmaceutical Research 21 (8), 1440-1444.

Nijdam, J.J., Langrish, T.A.G., 2006. The effect of surface composition on the functional properties of milk powders. Journal of Food Engineering 77 (4), 919925.

Ohtani, T., Yoshino, T., Hagiwara, S., Maekawa, T., 2000a. High-resolution imaging of starch granule structure using atomic force microscopy. Starch - Stärke 52 (5), 150-153.

Ohtani, T., Yoshino, T., Ushiki, T., Hagiwara, S., Maekawa, T., 2000b. Structure of rice starch granules in nanometre scale as revealed by atomic force microscopy. Journal of Electron Microscopy 49 (3), 487-489.

Olivares, M.L., Passeggi Jr., M.C.G., Ferrón, J., Zorrilla, S.E., Rubiolo, A.C., 2010. Study of milk/kappa-carrageenan mixtures by atomic force microscopy. Food Hydrocolloids 24 (8), 776-782.

Ortega-Rivas, E., 2009. Bulk properties of food particulate materials: an appraisal of their characterisation and relevance in processing. Food and Bioprocess Technology 2 (1), 28-44.

Paramita, V., Iida, K., Yoshii, H., Furuta, T., 2010. Effect of feed liquid temperature on the structural morphologies of $d$-limonene microencapsulated powder and its preservation. Journal of Food Science 75 (1), E39-E45.

Parker, M.L., Kirby, A.R., Morris, V.J., 2008. In situ imaging of pea starch in seeds. Food Biophysics 3 (1), 66-76.

Perea, M.J., Arzate, I., Terres, E., Alamilla, L., Calderon, G., Guttierrez, G.F. Garibay, V., Chanona J.J., 2009. Morphological characterization of powder milk and their relationship with rehydration properties. En Proceedings of the 5th CIGR Section IV International Symposium on Food 439 Processing, Monitoring Technology in Bioprocesses and Food Quality Managemen, Potsdam, Germany.

Prego, I., Maldonado, S., Otegui, M., 1998. Seed structure and localization of reserves in chenopodium quinoa. Annals of Botany 82 (4), 481-488.

Prom-u-thai, C., Huang, L., Rerkasem, B., Thomson, G., Kuo, J., Saunders, M., Dell, B., 2008. Distribution of protein bodies and phytate-rich inclusions in grain tissues of low and high iron rice genotypes. Cereal Chemistry 85 (2), 257-265.

Qi, P.X., 2007. Studies of casein micelle structure: the past and the present. Le Lait $87(4-5), 21$.

Quiroga, C.C., Bergenståhl, B., 2007. Characterization of the microstructure of phase segregated amylopectin and $\beta$-lactoglobulin dry mixtures. Food Biophysics 2 (4), 172-182

Rayas-Duarte, P., Robinson, S.F., Freeman, T.P., 1995. In situ location of a starch granule protein in durum wheat endosperm by immunocytochemistry. Cereal Chemistry 72 (3), 269-274.

Ridout, M.J., Parker, M.L., Hedley, C.L., Bogracheva, T.Y., Morris, V.J., 2004. Atomic force microscopy of pea starch: origins of image contrast. Biomacromolecules 5 (4), 1519-1527.

Riganakos, K.A., Demertzis, P.G., Kontominas, M.G., 1989. Gas chromatographic study of water sorption by wheat flour. Journal of Cereal Science 9 (3), 261-271.
Riganakos, K.A., Demertzis, P.G., Kontominas, M.G., 1994. Water sorption by wheat and soy flour: comparison of three methods. Journal of Cereal Science 20 (1), 101-106.

Round, A.N., Rigby, N.M., MacDougall, A.J., Morris, V.J., 2010. A new view of pectin structure revealed by acid hydrolysis and atomic force microscopy. Carbohydrate Research 345 (4), 487-497.

Rousset, Ph., Sellappan, P., Daoud, P., 2002. Effect of emulsifiers on surface properties of sucrose by inverse gas chromatography. Journal of Chromatography A 969 (1-2), 97-101.

Rouxhet, P.G., Genet, M.J., 2011. XPS analysis of bio-organic systems. Surface and Interface Analysis 43 (12), 1453-1470.

Rouxhet, P.G., Misselyn-Bauduin, A.M., Ahimou, F., Genet, M.J., Adriaensen, Y., Desille, T., Bodson, P., Deroanne, C., 2008. XPS analysis of food products: toward chemical functions and molecular compounds. Surface and Interface Analysis 40 (3-4), 718-724.

Russell, P.L., Gough, B.M., Greenwell, P., Fowler, P., Munro, H.S., 1987. A study by ESCA of the surface of native and chlorine-treated wheat starch granules: the effects of various surface treatments. Journal of Cereal Science 5 (1), 83-100.

Saad, M., Gaiani, C., Scher, J., Cuq, B., Ehrhardt, J.J., Desobry, S., 2009. Impact of regrinding on hydration properties and surface composition of wheat flour. Journal of Cereal Science 49 (1) 134-140.

Saad, M., Gaiani, C., Mullet, M., Scher, J., Cuq, B., 2011a. X-ray photoelectron spectroscopy for wheat powders: measurement of surface chemical composition. Journal of Agricultural and Food Chemistry 59 (5), 1527-1540.

Saad, M., Sadoudi, A., Rondet, E., Cuq, B., 2011b. Morphological characterization of wheat powders, how to characterize the shape of particles. Journal of Food Engineering $102(4), 293-301$

Sanyal, B., Chawla, S.P., Sharma, A., 2009. An improved method to identify irradiated rice by EPR spectroscopy and thermoluminescence measurements. Food Chemistry 116 (2), 526-534

Shrestha, A.K., Howes, T., Adhikari, B.P., Wood, B.J., Bhandari, B.R., 2007. Effect of protein concentration on the surface composition, water sorption and glass transition temperature of spray-dried skim milk powders. Food Chemistry 104 (4), 1436-1444.

Smith, D.S., Mannheim, C.H., Gilbert, S.G., 1981. Water sorption isotherms of sucrose and glucose by inverse gas chromatography. Journal of Food Science 46 (4), 1051-1053.

Stevens, J.S., Schroeder, S.L.M., 2009. Quantitative analysis of saccharides by X-ray photoelectron spectroscopy. Surface and Interface Analysis 41 (6), 453-462.

Ticehurst, M.D., York, P., Rowe, R.C., Dwivedi, S.K., 1996. Characterisation of the surface properties of alpha-lactose monohydrate with inverse gas chromatography, used to detect batch variation. International Journal of Pharmaceutics 141 (1-2), 93-99.

Tomoaia-Cotisel, M., Cioica, N., Cota, C, Racz, C, Petean, I, Bobos, L.D., Mocanu, A, Horovitz, O., 2010. Structure of starch granules revealed by atomic force microscopy. Studia Universitatis Babes-Bolyai Chemia 2 (2), 313-324.

Ulusoy, U., 2008. Application of ANOVA to image analysis results of talc particles produced by different milling. Powder Technology 188 (2), 133-138.

Vega, C., Kim, E.H.J., Chen, X.D., Roos, Y.H., 2005. Solid-state characterization of spray-dried ice cream mixes. Colloids and Surfaces B: Biointerfaces 45 (2), 6675.

Vignolles, M.-L., Lopez, C., Ehrhardt, J.J., Lambert, J., Méjean, S., Jeantet, R., Schuck, P., 2009. Methods' combination to investigate the suprastructure, composition and properties of fat in fat-filled dairy powders. Journal of Food Engineering 94 (2), 154-162.

Waduge, R.N., Xu, S., Seetharaman, K., 2010. Iodine absorption properties and its effect on the crystallinity of developing wheat starch granules. Carbohydrate Polymers 82 (3), 786-794.

Whistler, R.L., Turner, E.S., 1955. Fine structure of starch granule sections. Journal of Polymer Science 18 (87), 153-156.

Wuttisela, K., Triampo, W., Triampo, D., 2009. Chemical force mapping of phosphate and carbon on acid-modified tapioca starch surface. International Journal of Biological Macromolecules 44 (1), 86-91.

Zhou, Q., Cadwallader, K.R., 2004. Inverse gas chromatographic method for measurement of interactions between soy protein isolate and selected flavor compounds under controlled relative humidity. Journal of Agricultural and Food Chemistry 52 (20), 6271-6277.

Zhou, Q. Cadwallader, K.R, 2006. Effect of flavor compound chemical structure and environmental relative humidity on the binding of volatile flavor compounds to dehydrated soy protein isolates. Journal of Agricultural and Food Chemistry 54 (5), 1838-1843.

Zimm, B., Lundberg, J.L., 1956. Sorption of vapours by high polymers. Journal of Physical Chemistry 60 (4), 425-428. 